\title{
Peers, Parents, and Attitudes about School
}

\author{
Jonathan Norris*
}

\begin{abstract}
Educational attitudes are linked to long-term educational success through motivating effort and greater attention to the future. This study focuses on the role of friends and of parents in the school grade cohort in shaping adolescent attitude development. First, I explore the effect of friends' attitudes on an adolescent's attitudes. Second, I ask whether parental investments and educational expectations in the adolescent's school cohort can moderate the influence of friends on attitudes. I find that adolescents' attitudes about school respond to friends' attitudes and that parental educational expectations within a cohort can moderate the influence of friends on attitudes.(JEL C31, I21, Z13)
\end{abstract}

Keywords Skill Development, Attitudes, Peer Effects, Friendship Networks

\section{Introduction}

Socio-emotional skills develop during childhood and partly determine educational and economic outcomes (Attanasio 2015; Deming 2017; Heckman, Humphries, and Kautz 2014). While cognitive skills are most malleable during very early life, socio-emotional, or noncognitive, skills appear to remain malleable into adolescence (Heckman and Mosso 2014). An important component of these skills are attitudes and aspirations for education. In psychology, attitudes are a key predictor in the theory of planned behavior, and descriptive evidence consistently points toward a positive association between attitudes and educational outcomes (Lipnevich, Gjicali, and Krumm 2016). Also, attitudes may have an immediate effect on effort as experimental evidence indicates that students appear to choose effort not only by extrinsic rewards but also by intrinsic motivation (Koch, Nafziger, and Nielsen 2015). Thus, it is important to understand sources of influence on attitude development.

*E-mail Address: jonathan.norris@strath.ac.uk. The University of Strathclyde Department of Economics. Special thanks are due Jeremy Bray, Jane Fruehwirth, Dora Gicheva, Martijn van Hasselt, Rachel Kranton, Martin Andersen, Marie Hull, Otto Lenhart, and three anonymous reviewers for many helpful comments, suggestions, and insight. I also thank seminar participants at UNC Greensboro and Ida Johnsson for additional comments and support. 
I study two sources of influence on attitude development. First, I examine the role of social influence through friendship networks. The economics literature has for some time recognized that social influences can affect educational and life outcomes (Akerlof 1997; Akerlof and Kranton 2002; Becker 1994; Norris 2019). Moreover, the social psychology literature finds that during adolescence social relationships outside of the home take on increased significance for development (Bagwell and Schmidt 2013; Mak, Fosco, and Feinberg 2018). Thus, social influence may have a direct role in shaping attitudes that has not received much attention.

Second, I test whether what parents do at the broader school grade cohort level can shape network influence on attitudes. This is motivated both by the psychological literature and the economics literature on noncognitive skills. The psychological literature suggests that a combination of parent and friend relationships become key determinants for adolescent outcomes, implying it is important to understand their joint role (Zhang et al. 2018).

The economic literature on noncognitive skills has found considerable evidence that parental investments during a child's early life have a positive influence on skill development and that the lack of investment creates disadvantage (Attanasio et al. 2015; Fiorini and Keane 2014; Cunha, Heckman, and Schennach 2010; Cunha and Heckman 2008; Bono et al. 2016). ${ }^{1}$ However, less is known about whether parental actions create spill-overs across school cohorts and whether this may impact social influence from friends and peers during adolescence. Further, this literature suggests that early investments boost the effectiveness of later investments. To take advantage of this, requires understanding how key channels of influence interact with skills during adolescence. I add to the literature on peer effects and investments in skills by testing whether what the parents of peers do in one's broader cohort shapes the effect of friendship networks.

I examine these sources of influence on attitude development in two steps. I begin by estimating the effect of friend attitudes on own-attitudes. To do this, I use data from the National Longitudinal Study of Adolescent to Adult Health (Add Health) with its school based design and information on friendship nominations to construct social networks in schools. ${ }^{2}$ I then construct instruments from the architecture of the

1. See Heckman and Mosso (2014) for a review.

2. This research uses data from Add Health, a program project designed by J. Richard Udry, Peter S. Bearman, and Kathleen Mullan Harris, and funded by a grant P01-HD31921 from the Eunice Kennedy Shriver National Institute of Child Health and Human Development, with cooperative funding from 17 other agencies. Special acknowledgment is due Ronald R. Rindfuss and Barbara Entwisle for assistance in the original design. Persons interested in obtaining Data Files from Add Health should contact Add Health, The University of North Carolina at Chapel Hill, Carolina Population Center, 206 W. Franklin Street, Chapel Hill, NC 27516-2524 (addhealth_contracts@unc.edu). No direct support was received from grant P01-HD31921 for this analysis. This research did not 
network, using partially overlapping friend groups (Bramoullé, Djebbari, and Fortin 2009). Partially overlapping groups occur where an adolescent has friends of friends who are not their own friends. The characteristics of adolescents who are two-steps away in the network then form instruments under the assumption that these will impact the attitudes of friends but not the attitudes of the adolescent.

This approach requires both the relevance of these instruments for friend attitudes and the valid exclusion of them from the attitude equation. ${ }^{3}$ I therefore consider a broad range of robustness checks designed to account for potential selection effects into friend groups and other sources of unobserved heterogeneity. Additionally, I draw from recent work by Fruehwirth, Iyer, and Zhang (2018) to consider a different instrument that is based on plausibly random variation in attitudes across precise cohorts within a school. ${ }^{4}$ I find a highly robust estimate of friend attitudes that suggests friends can exert significant influence on attitude development.

I also extend this first step and examine nonlinearities (section 4.3) and the characteristics of those adolescents most likely to maximize the impact of an intervention based on the estimate of network effects (section 4.4). The latter indicates that well connected adolescents who hold poor attitudes and experience poor environments and parental investments represent those most likely to maximize the returns to intervention efforts on attitudes. Further, this result implies peer networks can magnify determinants of inequality when those exposed to poor investments and environments are tightly knit in their social network.

In the second step, I turn to evaluate whether school-grade peers' parents' educational expectations and involvement can moderate the effect of friends. ${ }^{5}$ In section 5, I discuss intuition around two possible mechanisms that can generate this moderating effect. These are focused around two cases. One, parental involvement and/or educational expectations may serve to protect an adolescent from friend group influence, thus as more parents are involved and/or raise their educational expectations in a school cohort, then a greater share of adolescents in the cohort are protected from friend influence thereby diminishing the strength of friend effects across the network. Second, as a greater share of parents in the cohort are involved or raise their expectations, then this could create a substitution effect between local (e.g. friend)

receive any specific grant from funding agencies in public, commercial, or not-for-profit sectors.

3. In section 3, I provide more detailed discussion around both the interpretation of network effects and their identification.

4. I describe this in more detail later but the cohorts are defined as those sharing the same school-grade-race-gender-religious denomination.

5. It is of interest to ask directly about moderating effects from own-parents' actions. However, own-parents' actions are very likely simultaneously determined, measured with error, or threatened by a number of other unobservables. The path to reasonable identification of the cohort peers' parents actions is much clearer. 
group norms and global (e.g. school grade cohort) group norms that can diminish the strength of friend effects. ${ }^{6}$ In the case of these mechanisms, the existence of a moderating effect suggests that interventions positively shifting parental expectations or investments in a school grade cohort can reduce the influence of social interaction effects on attitudes.

To estimate the moderating effect, I rely on within school, across cohort variation that is plausibly random (Hoxby 2000). Assuming parents select into schools based on fixed school factors, the peers' leave-one-out mean will be exogenous. I discuss this further in section 5. Under this assumption, and those of the network model, I instrument both friend attitudes and its interaction with the cohort peers' variable. ${ }^{7}$ I find that school-grade peers' average expectations, but not involvement, exhibit a strong moderating effect on friend influence.

This study relates and contributes generally to a literature on peer effects. A broad range of topics have been explored including exposure to disruptive peers (Carrell, Hoekstra, and Kuka 2018), peer gender composition (Anelli and Peri 2016; Black, Devereux, and Salvanes 2013; Lavy and Schlosser 2011), and nonlinearities by peer ability (Sacerdote 2014). ${ }^{8}$ Also, using friendship data, a number of studies have investigated the impact of friends' in social networks on GPA, risky behaviors, and later life education outcomes. ${ }^{9}$ In general, I contribute to this literature by testing how adolescent's attitudes respond to their friends' attitudes.

Additionally, I contribute to a smaller literature on peers' parents. Cohort peer maternal labor supply during adolescence is related to girls' later own-labor supply, with the evidence pointing toward a norm shift mechanism (Olivetti, Patacchini, and Zenou 2018). For education, at Kindergarten peers' parents' education creates spillovers, partially working through shifts in teacher practices (Fruehwirth 2016). Further, Avvisati et al. (2014) study an experiment within Parisian middle schools aimed at increasing parents' involvement and attitudes about the school. They find children of treated parents improved on a range of academic and behavioral outcomes and that these improvements spilled over to untreated children in the classroom.

Perhaps most directly related to my focus on educational attitudes is the study by Bifulco, Fletcher, and Ross (2011). They find that the peer composition of college

6. In norm substitution case, it may be likely that to observe evidence for this mechanism we need to examine broader cohorts compared to more refined groups.

7. I use the interaction between my preferred second-order friend characteristic instrument and the peers' parents variable as an additional instrument.

8. See Sacerdote (2014) for an extensive review and discussion of this literature.

9. See Calvó-Armengol, Patacchini, and Zenou (2009), Fortin and Yazbeck (2015), GoldsmithPinkham and Imbens (2013), Hsieh and Lee (2016), Lin (2010, 2015), and Patachini, Rainone, and Zenou (2016, 2016). Results have pointed toward sizable effects across outcomes even after dealing with bias from possible endogenous network formation. 
educated mothers in high school-grade cohorts is related to near-term educational outcomes (e.g. graduate high school; attend college), but they find no evidence that it is related to a range of adolescent attitude variables. Bifulco et al. (2014) look at longer-term educational outcomes and find the influence of peer maternal education fades out by the late twenties, suggesting the near-term effect was an imitation influence that eventually wore off.

As Bifulco, Fletcher, and Ross (2011) point out, parental education should capture a fair degree of parental investments, thus based on their results we might expect peer parental expectations and involvement to be unrelated to attitudes. However, peer parental expectations and involvement may have more indirect roles through moderating influence on attitudes in friendship networks. While I find that peer maternal involvement does not have a moderating effect, expectations are different, suggesting cohort peers' parents' educational expectations can have an immediate impact through moderating network effects.

\section{Data, Variables, and the Adjacency Matrix}

\subsection{The Data}

I use data from Add Health. Add Health provides in-depth information on adolescents and school networks. The data collection design is a nationally representative sample of high schools, with over 90,000 students initially interviewed. The in-school survey asked respondents to nominate their 5 best male friends and 5 best female friends, allowing the construction of school friendship networks. The first wave was collected during the 1994-95 school year. A subset of this sample consisting of approximately 20,000 respondents was selected for an in-home survey. This survey provides much greater detail on an adolescent's activities, behaviors, outcomes, and parents. The in-home subsample, however, does not provide information on all students within a school except for the saturated sample.

The saturated sample is of sixteen schools and all students in these schools were selected for the in-home interview. ${ }^{10}$ Two were large schools, with one mostly white and in a mid-sized town, and the other ethnically diverse and in a major metropolitan area. The remaining schools were scattered between rural and urban areas, some public and some private. Between the in-school and in-home survey a number of the respondents cannot be correctly linked because of missing data in the friend nominations. Add Health re-collected the school friendship nominations for

10. Maximum sample is approximately 3,702 . 
the saturated schools in May of 1995, which re-gains many of the lost observations and places these friendship nominations closer to the actual dates of the in-home survey (occurred from May 1995-December 1995). ${ }^{11}$ I select this sample, with the May friendship nominations, to explore the impact of both friends and school-grade peers' parents' parenting on schooling attitudes.

In the supplementary appendix, table A1, I compare the non-saturated, in-home sample to the saturated sample across the primary variables of interest. Detailed description of these variables is provided below. The sample sizes are post-removal of missing observations in each sample. In most cases, the mean differences are statistically significant but always small in magnitude. In general, the saturated sample remains very similar to the rest of the in-home sample, suggesting the Add Health survey design adequately preserved the representativeness of the sample in their selection of the saturated schools. ${ }^{12}$

\section{$2.2 \quad$ Variables}

While the noncognitive literature suggests that attitudes are likely important during development, they are indeed difficult to measure. Thus, I select measures that feasibly related to attitudes about school and use a factor analysis to develop an index of attitudes. The variables, or measures, used in the factor analysis are scale type questions and consist of the following set: how much a respondent reports a desire to go to college, how likely they think it is they will go to college, whether they feel a part of their current school, are happy at their current school, feel that their teachers are fair, and feel close to people at their school. Factor analysis maps the relation of a set of measures to potential underlying latent variables that explain the measures. The linear measurement equation with $j$ measures and $M_{j}$ the $\mathrm{j}$-th indicator and a set of $p$ latent factors $\mathbf{F}_{p}$ is

$$
M_{j}=\sum_{p=1}^{p} F_{p} \alpha_{j p}+\eta_{j} .
$$

The error term, $\eta_{j}$, allows each equation to be measured with error. The factor loadings are $\alpha_{j p}$. I run the factor analysis after deleting missing observations in the

11. All questions in the home survey related to schooling or other activities refer the respondent to answer for the 1994-1995 school year explicitly. The initial friendship nomination collection occurred towards the beginning of the 1994-1995 school year.

12. There are some differences in the racial composition. Hispanics are are $4 \%$ higher, blacks $7.7 \%$ lower, and other race is $8 \%$ higher in the saturated sample. White race is $50 \%$ compared to $54.7 \%$ in the non-saturated schools, suggesting the overall representation of majority to minority is fairly even between the samples. 
attitude measures. Only a small number are lost and the factor analysis sample size is 3,596 .

I find that all attitude measures load strongly on a single factor, thus I extract one factor that is a normalized predicted score based on the factor loadings from each measure and call this the attitudes about school scale, or just attitudes. I provide further information, summary statistics for each measure, and results from the factor analysis in the supplementary appendix section A. I also show that the attitudes index constructed from the factor loadings and these measures is strongly related to later-life educational attainment. These results are suggestive that the constructed index captures an important feature of adolescent attitude development.

I first focus on friend effects in attitudes (section 4.1) and then turn (section 5) to test whether the same school-grade (SG) peers parents' can have a moderating effect on friend influence. In this case, I focus on the leave-one-out mean of a scale for parental educational expectations and on a scale for activity investments with the adolescent. For educational expectations, Add Health asks the adolescent to report on a one-five scale (one is low, five is high) how disappointed their mother would be if they do not graduate from college and another for failure to graduate from high school. These questions are repeated for the father. For activity investments, Add Health asks the adolescent a series of ten questions regarding whether the adolescent has done a number of activities, such as played a sport, talked about school work, etc., during the past four weeks with their mother and again for the father.

Summary statistics for the expectations measures are reported in the supplementary appendix table B1 across the full sample dropping missing observations and the factor analysis sample conditioned on non-missing between mothers and fathers. For both mothers and fathers, the mean expectations for college and high school remain almost identical in the factor analysis sample compared to the full sample. For expectations, I run the factor analysis jointly on the mother and father variables. ${ }^{13}$ In supplementary appendix table B2, I report the loadings from the first factor. ${ }^{14}$ All four expectations measures load strongly on a single factor, which I then use to generate a parental expectations scale. To avoid lost observations, I generate the scale for mothers and fathers separately using the predicted factor scores, then I take the average of the mother and father expectations scale if both are non-missing or only the mother if the father's scale is missing and vice-versa, and finally, standardize the scale.

13. Two measures alone are not enough to appropriately conduct factor analysis, thus I must use all four together

14. Only the first factor explains a greater share of the variance than a single variable and it by far explains the largest proportion of variance, thus I only report loadings for this factor. 
For activity investment measures, table B1 reports only the sample with missing observations removed among the mother's measures and missing removed among the father's measures. ${ }^{15}$ Because these measures are binary, I use the polychoric correlation matrix to run the factor analysis. I do these separately for the mother and father, because each have 10 measures and there are many more missing fathers than mothers, as demonstrated by the sample sizes in B1. Factor loadings for each parent on each measure are also reported in table B2. Again, for each parent only a single factor well explains the shared variance in the measures. To form the parental investments scale, I first generate the predicted factor for mothers and fathers based on their loadings. Second, I take the average of these two scales if both are nonmissing or take the mother's scale if the father is missing and vice-versa and then standardize the scale.

Finally, I take the leave-one-out mean of the same school-grade peers' parental expectations and parental investments for use in examining moderating effects on friend attitude influence. Also, because of missing fathers, I additionally focus on the peer mothers' expectations alone. In this case, because the college scale exhibits much greater variance and represents higher academic expectations I use the leaveone-out mean of peer mother's collegiate expectations. Likewise, for investments I also consider the peer maternal investment scale separate from the combined scale.

The remainder of the variables cover controls for characteristics and environments that may influence the outcomes or network formation through homophily (Jackson 2011). These controls are parental education, an indicator for a single parent household, the number of siblings in the home, gender, ethnicity, and grade-level indicators in school. As part of the main control set, I sometimes include or exclude the Add Health Peabody Picture Vocabulary test scores normalized to mean zero and a standard deviation of one, as a proxy for ability. Parental education, in this study, refers to the highest level of parental education in the household. It proxies socio-economic status or simply the information available to the adolescent on the returns to education. Additionally, the indicator for a single parent household and the number of siblings in the home are included to capture more information about the family background.

\subsection{The Adjacency Matrix}

Add Health asked respondents for up to ten friendship nominations. From these, school friendship networks can be constructed as a spatial weights adjacency matrix $(\mathbf{G})$, with nominations defining the links in the matrix. The adjacency matrix is

15. In these measures, they are either all missing or all complete. 
defined as a block-diagonal, row-normalized directed graph. ${ }^{16}$ Each school network enters on the diagonal with zeros elsewhere.

One concern may be the cap limit on friend nominations. In the saturated sample prior to deletion of observations with missing data, only $0.33 \%$ of adolescents (12 out of 3614) nominated friends for all 10 slots. In the final sample, only two have nominated all 10 slots and 21 adolescents nominate 9 slots. Still, that the limit was for 5 male and 5 female friends may raise concern. However, in the full sample only $2.7 \%$ (97 out of 3614) name 5 or more female friends and only $2.1 \%$ (75 out of 3614 ) name 5 male friends. Thus, it does not appear that the cap limit on nominations is a problem for the choice of self-identified friends. ${ }^{17}$

Some respondents have all friendship nomination slots missing. I drop these observations to avoid row entries that contain all zeros in the adjacency matrix and also drop those with missing values attitudes and the control variables defined above. In the final sample construction, each individual has sent at least one link and receives at least one, and the sample size is 2,216 adolescents. ${ }^{18}$

\subsection{Summary Statistics}

In table 1, I report the summary statistics for the variables with the initial sample, after deletion of missing data, the analysis sample after construction of the directed graph adjacency matrix, and the p-values for testing mean differences between the initial and final selected sample. For the majority of variables, the summary statistics remain consistent across the samples. With deletion of missing observations (column 3 ), very little changes. With the dropping of isolated observations for the analytic sample (column 5), mean attitudes and test scores increase (0.098 and 0.129) and the differences from column 1 are statistically significant. Both attitudes and test scores are normalized to approximately mean zero and a standard deviation of one thus positive values indicate being above average. This implies that deleted isolated adolescents from the directed graph construction have lower attitudes and lower verbal reasoning skills.

Demographically, the compositional changes are minor. The largest changes are among black adolescents who fall from a 15 to a near 12 percent share and Hispanics

16. All rows sum to one.

17. Griffith (2019) carefully examines this issues and shows that censoring can result in an underestimation of the peer effect. He documents that in the large, Add Health in-school sample a substantial enough share of students hit the limit for female and male friends to be a concern. However, as documented here censoring is far less substantial in the saturated sample and less of a concern.

18. When deleting observations with missing friendship nominations, one small school is lost leaving 15 schools total. 
who fall from a 20 to a near 18 percent share. In general, conditioning on the nonisolated sample does imply a sample with somewhat better attitudes and test scores but one that is otherwise very similar to the full, saturated school sample. Thus, I consider the results to follow as conditional on being linked within the larger school network. However, in the robustness checks I consider imputation methods to test against the results being driven by the sample selection.

Table 1: Summary Statistics

\begin{tabular}{|c|c|c|c|c|c|c|c|}
\hline & \multicolumn{2}{|c|}{$\begin{array}{l}\text { Pre-Deletion } \\
\text { of Missing }\end{array}$} & \multicolumn{2}{|c|}{$\begin{array}{l}\text { Post-Deletion } \\
\text { of Missing }\end{array}$} & \multicolumn{2}{|c|}{$\begin{array}{c}\text { Post-Deletion } \\
\text { of Isolated }\end{array}$} & \multirow{2}{*}{$\begin{array}{c}\text { P-value Mean } \\
\text { Differences }\end{array}$} \\
\hline & Mean & $\mathrm{SD}$ & Mean & $\mathrm{SD}$ & Mean & $\mathrm{SD}$ & \\
\hline Attitudes & 0.000 & $(1.000)$ & 0.013 & $(0.987)$ & 0.098 & $(0.952)$ & 0.000 \\
\hline Highest Parental Edu & 13.530 & $(2.756)$ & 13.547 & $(2.742)$ & 13.664 & $(2.726)$ & 0.000 \\
\hline Single Parent H.H. & 0.275 & $(0.447)$ & 0.274 & $(0.446)$ & 0.259 & $(0.438)$ & 0.009 \\
\hline Number of Siblings & 1.479 & $(1.227)$ & 1.493 & $(1.209)$ & 1.513 & $(1.189)$ & 0.048 \\
\hline Female & 0.489 & $(0.500)$ & 0.497 & $(0.500)$ & 0.494 & $(0.500)$ & 0.505 \\
\hline Hispanic & 0.204 & $(0.403)$ & 0.198 & $(0.399)$ & 0.182 & $(0.386)$ & 0.000 \\
\hline Black & 0.151 & $(0.358)$ & 0.151 & $(0.358)$ & 0.118 & $(0.322)$ & 0.000 \\
\hline Other & 0.159 & $(0.366)$ & 0.150 & $(0.357)$ & 0.167 & $(0.373)$ & 0.096 \\
\hline White & 0.485 & $(0.500)$ & 0.500 & $(0.500)$ & 0.533 & $(0.499)$ & 0.000 \\
\hline Grade 7 & 0.076 & $(0.266)$ & 0.077 & $(0.267)$ & 0.069 & $(0.254)$ & 0.057 \\
\hline Grade 8 & 0.081 & $(0.273)$ & 0.085 & $(0.279)$ & 0.072 & $(0.258)$ & 0.016 \\
\hline Grade 9 & 0.103 & $(0.304)$ & 0.111 & $(0.314)$ & 0.132 & $(0.338)$ & 0.000 \\
\hline Grade 10 & 0.257 & $(0.437)$ & 0.267 & $(0.442)$ & 0.272 & $(0.445)$ & 0.011 \\
\hline Grade 11 & 0.243 & $(0.429)$ & 0.250 & $(0.433)$ & 0.257 & $(0.437)$ & 0.013 \\
\hline Grade 12 & 0.214 & $(0.410)$ & 0.210 & $(0.407)$ & 0.199 & $(0.399)$ & 0.005 \\
\hline Pic Voc Test Scores & -0.000 & $(1.000)$ & 0.029 & $(0.976)$ & 0.129 & $(0.939)$ & 0.000 \\
\hline Observations & $\begin{array}{l}\text { Max } \\
=3702\end{array}$ & & 3222 & & 2216 & & \\
\hline
\end{tabular}

\footnotetext{
Note: The P-values for mean differences refers to mean differences between the sample pre-deletion of missing and the final selected sample post-deletion of isolated.
}

Additionally, summary statistics for the peers' parental expectations and investment variables across the full sample and final selected sample are reported in the supplementary appendix table B3. ${ }^{19}$ The differences are minor and only significant in the SG peer parental investments scale.

19. Where the peer parental variables are missing in the analytic sample defined by column 5 in table 1, I impute them to the mean and control for a missing indicator in all analysis. 


\section{Empirical Model and Identification}

\subsection{Empirical Model}

There are $s=1, \ldots, \bar{s}$ school networks and $n_{s}$ adolescents in a school with $N=$ $\sum_{s=1}^{\bar{s}} n_{s}$ the total sample size. Let $\mathbf{Y}$ be an $N \times 1$ vector of attitudes and $\mathbf{G}$ the adjacency matrix from friendship nominations. Let $\mathbf{X}_{1}$ be an $N \times k_{1}$ matrix of the control variables where these are defined by those in table $1 .{ }^{20}$ School grade fixed effects are included in $\mathbf{X}_{1}$ and separate school fixed effects through $\mathbf{l}$, a vector of ones, and $\kappa_{s}$ the school intercept. The baseline specification is

$$
\mathbf{Y}=\mathbf{l} \kappa_{s}+\lambda \mathbf{G Y}+\mathbf{X}_{1} \beta_{1}+\mathbf{G X}_{2} \beta_{2}+\epsilon
$$

$\epsilon_{s}$ is an i.i.d error component. $\lambda$ is the endogenous social interaction effect that captures the simultaneous effect of friend attitudes on own-attitudes. Because $\mathbf{G}$ is row-normalized $g_{i j}=1 / n_{s i}$, with $n_{s i}$ the number of links an adolescent has in their school-network, GY returns the average of friend attitudes, and because the friendship nominations are unique to each individual, average friend attitudes are individual specific. Likewise, $\mathbf{G X}_{2}$ returns friend averages for each control variable, where the school grade fixed effects in $\mathbf{X}_{1}$ have been replaced with a continuous grade-level variable. ${ }^{21} \beta_{1}$ is the $k_{1} \times 1$ vector of own-coefficients and $\beta_{2}$ is the $k_{2} \times 1$ vector of coefficients for the average of control variables among one's friends.

The coefficient of interest is $\lambda$. There are two broad concerns for analyzing its estimate. One, is the interpretation, and two, is the identification. I discuss these in turn with implications for this study.

\subsection{Interpretation}

Often, estimating social interaction effects is of interest to evaluate potential social multipliers. The reduced form of equation 2 suggests a multiplier of $1 /(1-\lambda)$. The presence of $\lambda>0$ indicates that a shock to the attitudes of any adolescent linked in the school-network will spread across the network. Interventions need not be large. Rather, boosting the attitudes of a few will have widespread effects. However, Boucher and Fortin (2016) show that this depends on the nature of social interactions.

20. The Picture Vocabulary test scores are first omitted and then included as a check in the main specification.

21. While I allow for nonlinearity in the mean of attitudes across grades, I keep this to a linear measure for friend average school grade-level to preserve degrees of freedom. 
Specifically, they define the following quadratic utility functions:

$$
\begin{aligned}
& u_{i}\left(\mathbf{Y}, c_{0}\right)=\left(c_{0}+\mathbf{X}_{1} \beta+\epsilon_{i}\right) y_{i}-\frac{y_{i}^{2}}{2}+\alpha_{1} y_{i} \mathbf{G} \mathbf{Y} \\
& v_{i}\left(\mathbf{Y}, c_{0}\right)=\left(c_{0}+\mathbf{X}_{1} \beta+\epsilon_{i}\right) y_{i}-\frac{y_{i}^{2}}{2}+\frac{\alpha_{2}}{2}\left(y_{i}-\mathbf{G Y}\right)^{2}
\end{aligned}
$$

The private component of utility does not change between equations, but the social component differs between complementarity in equation 3 and conformity in equation $4 .^{22}$ The first case suggests that the benefit of attitudes increases in the attitudes of an adolescent's friends. The second case suggests that social utility incentives derive from matching a norm - proxied by the average of friends' attitudes - consistent with models of social identity and conformity (Akerlof and Kranton 2002). ${ }^{23}$

These two sources of social influence have implications for the presence of a multiplier. The resulting reduced forms are

$$
\begin{aligned}
\mathbf{y}^{u}\left(c_{0}\right) & =\left(\mathbf{I}-\alpha_{1} \mathbf{G}\right)^{-1}\left(c_{0} \mathbf{1}+\mathbf{X} \beta+\epsilon\right) \\
\mathbf{y}^{v}\left(c_{0}\right) & =\left(\mathbf{I}-\frac{\alpha_{2}}{1+\alpha_{2}} \mathbf{G}\right)^{-1}\left(\frac{c_{0}}{1+\alpha_{2}}+\mathbf{X} \frac{\beta}{1+\alpha_{2}}+\frac{\epsilon}{1+\alpha_{2}}\right) .
\end{aligned}
$$

The multiplier effect is only present in equation 5 under complementarity (Boucher and Fortin 2016). For the conformity effect in equation 6, an adolescent imitates attitudes but shocks on attitudes have the same effect for everyone and the gap $\left(y_{i}-\mathbf{G} \mathbf{Y}^{2}\right)$ remains the same. The implication is that interventions must shift attitudes among a large enough share of the network to have an impact through the conformity effect.

Identification of these mechanisms is not a matter of endogeneity in the inputs. Exogenous variation in friend attitudes will not reveal complementarity or conformity. ${ }^{24}$ However, isolating exogenous variation will inform on the presence of social

22. Unique Nash equilibrium solutions hold if $\alpha_{1} \in[0,1)$ and $\alpha_{2} \geq 0$ (Boucher and Fortin 2016). 23. Note that despite the row-normalized assumption (local-average model) it still admits both a complementary, social multiplier, type model and/or a social conformity type model. Another approach to exploring the intensity of interactions is to forgo row-normalization and use the local aggregate model as in Liu, Patacchini, and Zenou (2014). My emphasis is on identifying the presence or absence of social influence in attitudes and testing the role of cohort peers' parents in moderating this influence. Thus, I focus on the local-average model that implicitly admits either social influence generating process.

24. Boucher and Fortin (2016) show that complementarity or conformity can be identified if we know who is not linked in the network. However, this likely works best in experimental designs since in survey data the isolated may have links that are missing. Liu et al. (2014) also examine these mechanisms through a local aggregate (non-row normalized network matrix) and the local average (row-normalized) peer effects and many instrument bias-corrected estimator. I do not pursue these extensions in this study. 
influence and allow exploration of potential policy relevant mechanisms. Moreover, despite the inability to conclude between complementarity and conformity, it is still possible to identify the key players who will help maximize an interventions impact and explore their characteristics. I return to this point with further details in section 4.4. Next, I discuss endogeneity concerns for the identification of $\hat{\lambda}$.

\subsection{Identification}

A number of concerns exist for the identification of a friend attitude effect. When individuals interact with all others in a group and group sizes do not vary, simultaneity introduces linear dependence between peer outcomes and peer characteristics that prevents separate identification of peer average outcome effects (endogenous effect) and contextual effects (peer characteristics) (Manski 1993). Further, simultaneity bias can result in an overestimation of the social interaction effect; although, in practice researchers often find that peer effect estimates increase upon instrumenting them (Caeyers and Fafchamps 2016). This is likely due to the exclusion bias. Caeyers and Fafchamps (2016) show that the leave-one-out mean construction, as in this study, mechanically generates a negative bias. ${ }^{25}$ However, they also show an instrumenting strategy removes this bias potentially resulting in an increase to the social interaction effect. $^{26}$

To correct for these problems, I use the method of partially overlapping peer groups to create a set of instruments. Assuming the network formation is exogenous, Bramoullé, Djebbari, and Fortin (2009) show that when individuals interact through networks the characteristics of second-order links $\left(\mathbf{G}^{2} \mathbf{X}_{2}\right)$ can serve as instruments for GY. A Taylor-series expansion of the inverse term in the reduced form equation illustrates the intuition. We have $(\mathbf{I}-\lambda \mathbf{G})^{-1}=\sum_{k=0}^{\infty}(\lambda \mathbf{G})^{k} \cdot{ }^{27}$ From equation 2 and the reduced form, we can obtain the expected mean friends' attitudes, as in Bramoullé, Djebbari, and Fortin (2009), given by

$$
\mathbb{E}(\mathbf{G} \mathbf{Y} \mid \mathbf{X})=\frac{\kappa}{(1-\lambda)} \mathbf{l}+\beta_{1} \mathbf{G X}_{1}+\left(\beta_{1} \lambda+\beta_{2}\right) \sum_{k=0}^{\infty} \mathbf{G}^{k+2} \mathbf{X}_{2}
$$

The $\mathbf{G}^{k+2} \mathbf{X}_{2}$ terms do not appear in the structural equation, suggesting them as instruments. Practically, researchers typically focus on $\mathbf{G}^{2} \mathbf{X}_{2}$, or a subset of them,

25. The intuition is that the leave-one-out mean contains the negative of own-attitudes and that the variance of the leave-one-out mean is related to the variance of the error term in equation 2 .

26. Key for this to work is that the individual's own value of the instrument is controlled for. The strategy introduced by Bramoullé, Djebbari, and Fortin (2009) satisfies this condition.

27. I replace the $\alpha$ 's with $\lambda$ as both data generating processes give the same result for empirical purposes here. 
for reasons of instrument strength.

With exogenous network formation and the presence of second-order links (friends of friends) that are not linked to the individual, social interaction effects are identified through these instruments (Bramoullé, Djebbari, and Fortin 2009). Intransitive triads (i linked to $\mathrm{j}$ linked to $\mathrm{k}$ ) ensure that $\mathbf{G}^{2}$ is not linearly dependent with $\mathbf{G}$. The full identification requirement is that $\mathbf{I}, \mathbf{G}$, and $\mathbf{G}^{2}$ be linearly independent, or if adding network fixed effects, to also include $\mathbf{G}^{3}$. Bramoullé, Djebbari, and Fortin (2009) suggest the following check: vectorize each matrix, concatenate the resulting vectors, and check whether the matrix formed from this concatenation has a rank of three (or four with $\mathrm{G}^{3}$ ). The Add Health networks in my sample pass this check (both with and without $\mathrm{G}^{3}$ ).

The presence of these groupings allows the influence of k's characteristics on j's attitudes to isolate exogenous shifts in i's attitudes in response to shifts in j's. ${ }^{28}$ Of course, k's characteristics need to be correlated with j's attitudes to achieve relevance of the instruments. Moreover, identification here hinges on network formation being exogenous, or exogenous conditional on the controls. This will fail, however, in the presence of shared environments that correlate with attitudes or unobserved determinants of network linking decisions. To control for shared environments, I include school fixed effects and consider additional measures in robustness checks.

Friend selection represents a particularly difficult challenge. The primary example is that of homophily bias. An adolescent selects their friends based on some shared, unobserved characteristics, such as ability, and this characteristic is also correlated with attitudes about school. The result is that individual and peer attitudes will be correlated even if there is no true effect. Yet, a number of studies that have used Add Health data and employed models of endogenous network formation have not found large reductions in their social interaction effect estimates across a range of outcomes (Badev 2013; Boucher and Fortin 2016; Goldsmith-Pinkham and Imbens 2013; Hsieh and Lee 2016).

This result may be due the rich set of controls available in Add Health that potentially capture the selection process. In this case, with a conditionally exogenous network, the variation in $\mathbf{G}^{2} \mathbf{X}_{2}$ should be as good as randomly assigned, as long as the $\mathbf{X}$ variables are also exogenous. Thus, the instrument should not be highly correlated with an adolescent's own-characteristics. In the results, I focus on the highest parental

28. One need not modify the $\mathbf{G}^{2}$ matrix to remove those who are both first-order and second-order peers. The presence of $\mathbf{G X}_{2}$ in both stages accounts for correlation due these individuals. It is required that second-order friends who are not also first-order (intransitive triads) friends exist else $\mathbf{G}^{2}$ will be linearly dependent on $\mathbf{G X}_{2}$ and identification will fail. Thus, identification is driven by the presence of friends of friends. 
education (PEDU) as the variable for the instrument set. ${ }^{29}$ So, I report balancing tests for $\mathbf{G}^{2} P E D U$ in the appendix table $\mathrm{C} 1$ panel A. Only for the race/ethnicity indicators do I find significant correlations, and in all cases, the correlation between the instrument and own-characteristics is near zero in magnitude. ${ }^{30}$ These results add weight to the idea that the rich control set has adequately captured correlation due a selection process. Nonetheless, I also consider a wide-range of robustness checks to guard against potential selection bias.

First, I turn to a recently developed estimator for peer effects by Johnsson and Moon (2017). This is a semiparametric control function approach, which consists of a first step network formation model developed in Graham (2017) and then uses information from the first step to estimate peer effects. The network formation model regressors are based on homophily and are the absolute value of the difference between two adolescents' characteristics. An adolescent can form a link or not with every other adolescent in their school-network, thus in dyad form, we have repeated observations on each individual. The Graham (2017) approach estimates the probability of two adolescents choosing to link based on these regressors and an individual fixed effect. From this step, Johnsson and Moon (2017) use the estimate of the fixed individual heterogeneity parameter to control out the endogeneity of the adjacency matrix $\mathbf{G}$. I describe details of this approach in appendix section D, and implement it as a robustness check.

Second, beyond just a selection concern, the exclusion restriction will be violated if an adolescent is directly influenced by second-order links, thus I consider an alternative instrument that does not rely on the network architecture. I draw from recent work in Fruehwirth, Iyer, and Zhang (2018) who study the effect of religiosity on mental health by instrumenting religiosity with the average religiosity of same schoolgrade-race-gender-religious denomination peers. The idea here is that if parents only select schools based on school-level characteristics, then variation across cohorts is random. This argument can be further relaxed by allowing for school-grade trends, which I also explore. Moreover, by defining a precise reference group they obtain this random variation from a group more likely relevant to an adolescent's choices.

I follow their approach and use the average attitudes within this same reference group as an alternative instrument. Panel B of the appendix table $\mathrm{C} 1$ also reports balancing tests for this instrument. They demonstrate a lack of correlation between

29. This provides the strongest relevance for the first-stage. I discuss this instrument in more detail in the results.

30. In the balancing tests, it is important to control for school fixed effects, parental education, and friend characteristics since these define the network and the instrument. Omitting them may suggest a correlation that is mechanical. 
it and observable controls further supporting the no selection effect argument. ${ }^{31}$

Third, I add school by grade fixed effects, control for $\mathbf{G}^{2} \mathbf{X}_{2}$ characteristics not in my preferred instrument set, and control for neighborhood level variables. These are aimed at shutting down bias potentially due to fixed factors at the schoolgrade cohort level (e.g. common teachers), direct correlation between friend of friend characteristics and attitudes, and possible neighborhood influences not absorbed by the school fixed effect.

\section{Results: Friend Attitudes}

\subsection{Baseline Estimates}

In table 2, I report the main results for the effect of friend attitudes on adolescent attitudes. In all specifications I control for the main controls (minus the test scores until column 5), friend averages on the controls, and school fixed effects. Column 1 shows the standard ordinary least square (OLS) result. The effect size is near 0.3 and highly significant. This estimate, of course, does not account for potential simultaneity bias or selection bias.

In column 2, I report 2SLS estimates using all $\boldsymbol{G}^{2} \boldsymbol{X}_{2}$ characteristics as instruments. The effect size increases but these estimates may not be reliable. The overidentification test is only past at the $10 \%$ level. Also, the first stage Kleibergen-Paap $\mathrm{F}$ (KP-F) statistic is very low (4.4) indicating potential weak instrument bias. I do report the conditional likelihood ratio (CLR) and the Lagrange multiplier (K) weak instrument robust tests of the null that $\lambda=0$. The CLR test passes at the $5 \%$ level but the $\mathrm{K}$ test only at the $10 \%$.

First-stage results are reported in the appendix, section E and table E1. Only the average of second-order links parental education has a strong and significant correlation with friend attitudes (column 1). In terms of relevance, this is sensible. I already expect attitudes to be strongly linked to education. We indeed see this expected pattern in the appendix figure A1 and table A4. Additionally, in these baseline specifications I find own-parents education to be significantly correlated with attitudes, at around a $2.5 \%$ standard deviation increase in attitudes for an extra year of education.

Thus, in columns 3-5 I restrict to just this instrument and maintain that restriction throughout the rest of this study. The second-stage result in column 4 is near 0.6 and

31. Again these tests include controls for the variables defining the reference group, corresponding friend variables, and school fixed effects to remove mechanical correlation due the reference group construction. 
the Kleibergen-Paap F is now quite strong alleviating concerns over weak instruments. The standard deviation of friend attitudes is reported in appendix table E2 and is 0.72. Using the estimated effect in column 4 and the sample standard deviation of friend attitudes, a one standard deviation increase in friend attitudes translates into approximately a 0.43 standard deviation increase in the attitudes index. This points to a strong influence within friend groups on the development of attitudes about school.

Table 2: Attitudes and Friends Attitudes

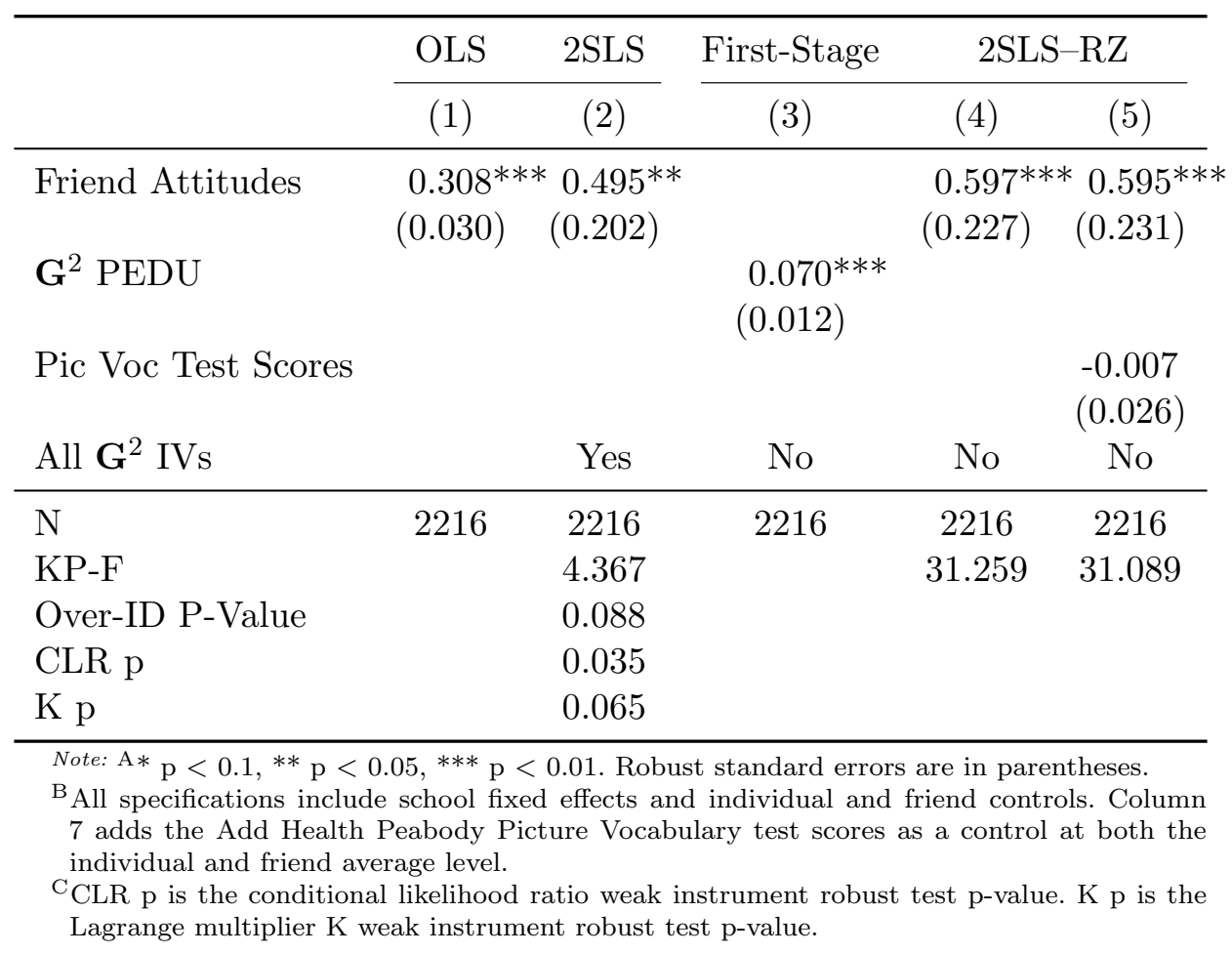

In column 5, I add the Add Health Picture Vocabulary test score to the main control set. I use this as a proxy for ability and potential friend selection bias around ability. The results here are essentially unchanged from those in column 4. Thus, with the full set of controls and school fixed effects I find significant social interaction effects in attitudes over networks.

Two points in summation before robustness checks. One, it is not surprising to find an increase in the social interaction effect after applying an instrument, as is the case here, because of exclusion bias (Caeyers and Fafchamps 2016). ${ }^{32}$ Two, the friend attitude effect estimates do not reveal whether the underlying model is one of complementarities (equation 3) or conformity (equation 4). Nonetheless, that friend

32. The exclusion bias from the leave-one-out friend average construction is always negative (Caeyers and Fafchamps 2016). If it dominates upward bias from simultaneity, then we should expect to see the instrumented effect size get larger. 
attitudes matter implies that the network matters for considering interventions to target attitude improvements. Thus, in section 4.4, I explore what characterizes the adolescents most likely to maximize intervention efforts if successfully targeted. Next, I explore a variety of robustness checks to test against potential violations of the identification assumption.

\subsection{Robustness Checks}

\subsubsection{Testing Against Exclusion Restriction Violations}

Selection bias may threaten my preferred instrument. For example, one may be concerned that second-order link parents' education may impact own-parents' input to the adolescent's friendship selection. In table 3, the first two columns report on the results from implementing the method by Johnsson and Moon (2017) to control for endogenous network formation. ${ }^{33}$ I again omit (column 1) and include (column 2) the picture vocabulary test score. The results indicate essentially no difference from the 2SLS results in columns 4-5 of the baseline. Taken at face-value allowing for endogenous network formation in the method of Johnsson and Moon (2017) suggests that indeed the friends of friends parental education instrument is not correlated with unobservables that predict friend selection. Nevertheless, this approach relies on a functional form restriction that the difference between two adolescents' characteristics predict network formation but not attitudes. So, in the remaining checks, I turn to an entirely new instrument.

In columns 3-4, I use the average of attitudes in the same school-grade-race-genderreligious (SGRGR) denomination peer reference group as an instrument for friend attitudes. Using this instrument, the sample size is slightly reduced $(N=2005)$. I first explore the results on this reduced sample size. In column 3, I omit the $\mathbf{G}^{2} P E D U$ instrument altogether. The estimated effect size is practically the same as the baseline result; although, it is less efficient. Also, instrument strength falls above the common cutoff rule of 10 at a KP-F of 15.88 .

Next, in column 4, I include both this new instrument and the $\mathbf{G}^{2} P E D U$ instrument. The estimated effect slightly increases but is highly consistent with the baseline result and efficient. The instruments also easily pass the overidentification test.

The remaining specifications consider extended checks around these two instruments. In column 5, I include a school-grade trend for attitudes to relax the assumption of parental selection based only on school-level characteristics. In column 6, I

33. See section D for details on this method. 
Table 3: Attitudes and Friends Attitudes: Robustness Checks

\begin{tabular}{|c|c|c|c|c|c|c|c|}
\hline & \multicolumn{2}{|c|}{ Endogenous G CFA } & \multicolumn{5}{|c|}{ 2SLS with additional IV } \\
\hline & (1) & $(2)$ & $(3)$ & $(4)$ & $(5)$ & $(6)$ & (7) \\
\hline Friend Attitudes & $\begin{array}{c}0.566^{* *} \\
(0.228)\end{array}$ & $\begin{array}{c}0.568^{* *} \\
(0.232)\end{array}$ & $\begin{array}{c}0.583^{*} \\
(0.318)\end{array}$ & $\begin{array}{l}0.644^{* * *} \\
(0.195)\end{array}$ & $\begin{array}{c}* 0.623^{* * *} \\
(0.199)\end{array}$ & $\begin{array}{c}* 0.622^{*} \\
(0.318)\end{array}$ & $\begin{array}{l}0.606^{* * *} \\
(0.184)\end{array}$ \\
\hline $\mathrm{G}^{2} \mathrm{IV}$ & Yes & Yes & No & Yes & Yes & No & Yes \\
\hline SGRGR IV & No & No & Yes & Yes & Yes & Yes & Yes \\
\hline School-Grade Trend & No & No & No & No & Yes & No & No \\
\hline SGRGR IV Impute & No & No & No & No & No & Yes & Yes \\
\hline AH PVT Control & No & Yes & No & No & No & No & No \\
\hline $\mathrm{N}$ & 2216 & 2216 & 2005 & 2005 & 2005 & 2216 & 2216 \\
\hline $\mathrm{KP}-\mathrm{F}$ & & & 15.878 & 19.816 & 18.462 & 17.194 & 24.038 \\
\hline Over-ID P-Value & & & & 0.810 & 0.733 & & 0.952 \\
\hline \multicolumn{8}{|c|}{$\begin{array}{l}\text { Note: A* } \mathrm{p}<0.1,{ }^{* *} \mathrm{p}<0.05,{ }^{* * *} \mathrm{p}<0.01 \text {. Robust standard errors are in parentheses. All specifications include } \\
\text { school fixed effects and the full set of individual and friend controls defined previously. } \\
\text { B The endogenous G CFA columns reports results from the method by Johnsson and Moon (2017). } \\
{ }^{\mathrm{C}} \mathbf{G}^{2} \text { IV represents the second-order friend average of highest parental education. } \\
\text { D SGRGR is the same school-grade-race-gender-religious denomination peer reference group definition. The SGRGR } \\
\text { IV is the average of attitudes at this reference group. } \\
\text { E SGRGR IV Impute means that missing observations in the SGRGR IV are set to the mean and I control for a } \\
\text { missing indicator. The missing indicator is included in both stages. } \\
\text { F AH PVT is the AH Peabody Picture Vocabulary test scores. }\end{array}$} \\
\hline
\end{tabular}

use only the SGRGR IV but impute it to the mean when missing and control for a missing indicator in both stages. In column 7 , I repeat this but also include the $\mathbf{G}^{2}$ instrument for overidentification. In each of these checks, the estimated effect of friend attitudes barely deviates from that of the baseline. The evidence in table 3 is consistent with the excludability of average second-order links' parental education and continues to suggest that friend attitudes bear significant influence.

Finally, in the appendix, table E3 I consider a set of additional checks. First, it is possible that adolescents sharing a common set of teachers have their attitudes influenced together. To check against this, I replace the school fixed effect with the school by grade fixed effect. Assuming students who share the same grade are more likely to share friendships and teachers, the friend attitude effect estimate will decrease in the presence of this bias. The estimate, however, remains highly similar to the baseline. I also repeat this specification adding the SGRGR IV and again find consistent evidence with the baseline.

Second, I add all $\mathbf{G}^{2} \mathbf{X}_{\mathbf{2}}$ variables other than the parental education instrument to the control set, as an attempt to account for potential variation in attitudes running from the second-order links. I do this with the baseline instrument and again adding the SGRGR IV and again find the friend attitude effect to remain consistent with the baseline results.

Third, neighborhood influences not accounted for by the school fixed effects 
could also violate the exclusion restriction, especially if parental education correlates within neighborhoods. Add Health links 1990 census information to the data. I draw out census block-level information on each adolescent's neighborhood percentage of college degrees among those aged 25 and older, unemployment rate, and the proportion that is white, black, Hispanic, and Asian/Pacific islander. I estimate three specifications: one controlling for these, another adding an interaction between the neighborhood college percentage and parental education, and another keeping the interaction and adding school by grade fixed effects and the SGRGR IV. Again, all friend attitude estimates continue to support the baseline result.

One potential weakness is that if a friend of a friend is a neighbor and the adolescent interacts with their parents the exclusion restriction could be violated. The neighborhood controls may pick up this correlation if they correlate with secondorder link parental education. Alternatively, the specification controlling for $\mathbf{G}^{2} \mathbf{X}_{2}$ may also pick up this correlation. However, I cannot completely rule out this threat; yet, wherever I include both the second-order link parental education instrument and the SGRGR IV, the overidentification test is easily past. Moreover, the combined set of results in this section consistently support the baseline estimate.

\subsubsection{Robustness: Network Simulations, Missing Links, and Lost Observations}

In this section, I consider a number of checks around network classification and sample selection bias. First, I simulate the network at random to test against the possibility that the baseline result is a mechanically driven correlation. I do this by randomly drawing links within each school network holding the density of links constant $^{34}$ for 1,000 draws and running the 2SLS estimator with $\mathrm{G}^{2} P E D U$ as the instrument. The intuition here is that if the correlation under the true network is not artificially a product of the network structure, then simulated results for $\hat{\lambda}$ should be centered around zero. ${ }^{35}$ In table, 4 I report the results. Consistent with the above expectation only $0.9 \%$ of the estimates are significantly different from zero $(10 \%$ level), and the median estimate is very near zero.

I also consider a simulation where I add some noise to the average of friend attitudes. Bias from measurement error in networks, such as misclassified links, can be non-classical, meaning potential upward bias (Advani and Malde 2018). Specifically, in two setups I draw a random variable $(\psi)$ centered around zero- such that the first allows $\psi$ to have a range corresponding to a standard deviation in friend attitudes

34. This holds the degree distribution constant.

35. We might expect the confidence intervals to be very wide because the first-stage should be uninformative. 
Table 4: Simulation Results

\begin{tabular}{lccc}
\hline & $\begin{array}{c}\text { Simulation } \\
\text { Random Network }\end{array}$ & \multicolumn{2}{c}{$\begin{array}{c}\text { Simulation } \\
\text { Noise in GY }\end{array}$} \\
\hline Percent Significant & $0.9 \%$ & $100 \%$ & $84.4 \%$ \\
Median $\hat{\lambda}$ & 0.007 & 0.598 & 0.600 \\
Mean $\hat{\lambda}$ & -13.989 & 0.604 & 0.724 \\
\hline Reps & 1000 & 1000 & 1000 \\
$\psi$ Min/Max & & 1 SD GY & 3 SD GY \\
\hline
\end{tabular}

and the second to three standard deviations - and add this to the friend mean. I draw $\psi 1000$ times and the friend attitude effect estimate at each repetition. In the first setup, the $\lambda$ estimate is always significant and the mean and median estimates are very similar and near the baseline. In the second setup, the $\lambda$ estimate is significant $84 \%$ of the time. The median remains similar to the baseline but the mean of the $\lambda$ estimates does rise.

Nonetheless, the result is relatively robust to additional noise. A substantial amount of noise is required to push the estimate upward. Moreover, Lewbel, Qu, and Tang (2019) find that the 2SLS estimate of $\lambda$ remains consistent in the presence of misclassification error, as long as this error grows slower than the growth of the sample size. ${ }^{36}$ Thus, these simulations and the results of Lewbel, Qu, and Tang (2019) suggest that misclassification would need to be pervasive to create a distortion in the 2SLS estimates.

A related misclassification concern is potential bias from missing data in the friend outcomes due to only partially observing the outcomes of network members in the data. This is a primary reason I use the saturated sample from Add Health that includes all network sampled adolescents in the in-home sample. Yet, a number of links are lost in the sample construction, so I consider two sensitivity tests reported in the supplementary appendix, section F.

In the first, I assume friendship reciprocity and construct the undirected graph. If someone nominates you as a friend, then both that person and you receive a link in the adjacency matrix. As a result, some observations are regained $(N=2977)$ that were dropped because of missing friendship nominations in the directed graph. Overall, these results are highly consistent with the baseline from the directed graph.

Second, I test against sample selection bias by allowing imputation. I recognize that one should be cautious with imputation when using 2SLS and I emphasize

36. For instance, this would be unlikely to hold if every link in the network has a positive probability of being misclassified, but it is more likely to hold as we indeed observe some portion of true links. 
that the primary point of the exercise is to check whether the effect sizes remain consistent with the baseline. I consider both multiple imputation and a simpler mean imputation with a missing indicator control. In either case, the estimate for friend attitude effects is very similar to the baseline result. While imputation does not provide a perfect test against bias from lost observations, it suggests that the results are not driven by sample selection issues.

\subsection{Nonlinearity and Friend Effects}

Next, I explore whether the friend attitude effect is nonlinear. It may be that the average effect varies depending on the level of friend attitudes. This will be important to understand if attempts to boost attitudes through network links can only work if the friend groups have a sufficient level of attitudes or conversely that they are not too high.

To test for nonlinear effects, I first take a control function approach, using the reduced form residuals as a control variable in the attitudes specification. This approach is more amendable to adding polynomials of the endogenous variable, because it does not require generating additional instruments.

Given equation 2 and a matrix $\mathbf{Z}=\left[\begin{array}{lll}\mathbf{X}_{1} & \mathbf{G X}_{2} & \mathbf{G}^{2} \mathbf{X}_{2}\end{array}\right]$, with $\mathbf{G}^{2} \mathbf{X}_{2}$ the excluded variables, ${ }^{37}$ the reduced form for friend attitudes is

$$
\mathbf{G Y}=\mathbf{Z} \pi+v
$$

With standard assumptions on instrument exclusion and relevance, one can obtain the same result as in 2SLS by controlling for $\hat{v}$ in equation 2 (Wooldridge 2015). The specification becomes

$$
\mathbf{Y}=\mathbf{l} \kappa_{s}+\lambda \mathbf{G} \mathbf{Y}+\mathbf{X} \beta_{1}+\mathbf{G X} \beta_{2}+\rho_{1} v+e
$$

with the $E(v e)=0$ and $E(\mathbf{G Y} e)=0$. Because $v$ is not observed, replace it with $\hat{v}$ and estimate by ordinary least squares. ${ }^{38} \mathrm{I}$ am interested in possible non-linear effects in friend attitudes, so I modify equation 9 by adding polynomials of GY. The CF approach does not require multiple reduced form equations as in a standard 2SLS, but it does require a stricter assumption that $(\epsilon, \mathrm{v})$ be independent of $\mathbf{Z}$ (Wooldridge 2007). Thus, the CF method has the advantage of being more parsimonious, albeit with added assumptions.

37. Restricted to friends of friends highest parental education in this case.

38. Standard errors need to be bootstrapped to correct for the generated regressor 
In table 5, I report the results from this CF approach including polynomials in friend attitudes. The specification in column 1 includes a polynomial of degree 2 , in column 2 of degree 3 , and in column 3 of degree 4 . The polynomial terms in columns 1 and 2 are negative and significant and the evidence comparing across specifications suggests that up to a degree 3 polynomial appears to be sufficient.

Using the specification in column 2, I calculate the marginal effect of friend attitudes from approximately one and a half standard deviations below and above the mean in half standard deviation steps and report these in figure H1 of the supplementary appendix. Friend effects are highly significant and near the baseline effect over the region of below average friend attitudes but slowly decline and become insignificant approximately one standard deviation above the mean. All else constant, the marginal impact of friends' attitudes increases as average friend attitudes fall.

Table 5: Nonlinear Effects in Friend Attitudes

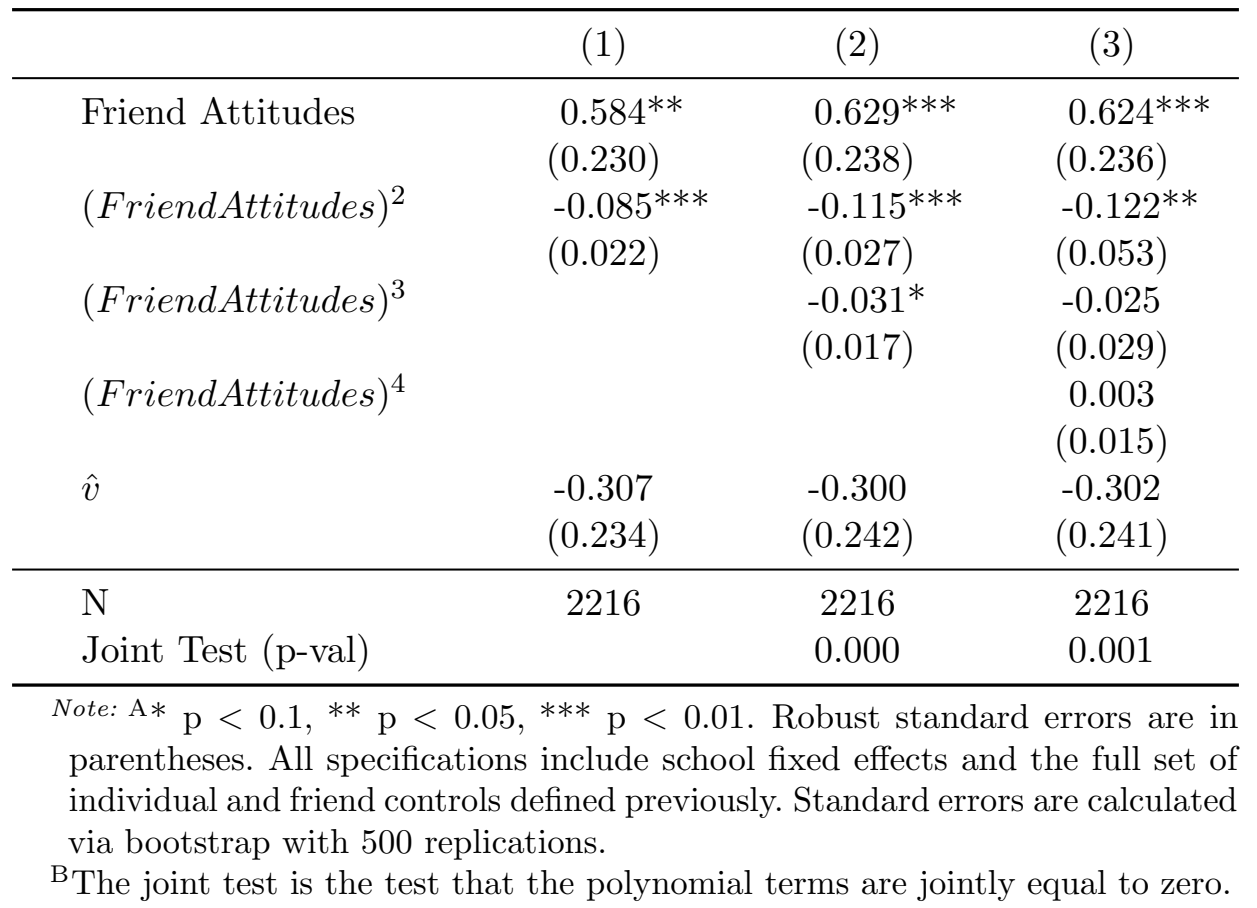

I also explore the nonlinearity in the effect of friend attitudes using nonparametric methods. I discuss these in the appendix, section $G$ and report the results in the appendix figure G1. Overall, these results largely agree with the suggestions from table 5 .

Friend attitudes appear to exert the strongest influence when they are relatively poor or at least not too high. Indeed, an adolescent whose social circle exhibits poor attitudes about school is the one who schools, communities, families, and policymakers may be concerned about. The evidence here indicates this concern is well 
founded and that interventions should carefully take into account the adolescents' friends.

\subsection{Key Players}

Building on the results thus far, interventions that care about educational attitudes may care about targeting the adolescents who will help generate the largest overall impact in a school. We know that when the underlying model is one of social conformity, social multipliers will not exist and a large enough share of a network must be targeted to generate impact. Still, we would like to know something about who to target to achieve the maximum return despite whether complementarities or conformity drive social interaction effects. Boucher and Fortin (2016) show that with an estimate of $\lambda$ we can explore this regardless of the underlying structural model.

A policymaker may desire to affect a particular subset of individuals $(I \subset N)$. For example, based on the nonlinearity results, we may aim to target adolescents on the lower end of the attitude distribution. From this subset, we can then define a key player framework. Based on the reduced form equations 5 and 6 , Boucher and Fortin (2016) write the overall impact of a shock $c$ on all adolescents in the subset $I$ as

$$
\tau c \mathbf{l}^{\prime}(\mathbf{I}-\lambda \mathbf{G})^{-1} \mathbf{e}_{\mathbf{I}}
$$

with $\lambda \in(0,1)$ and $\tau=1 /\left(1+\alpha_{2}\right){ }^{39}$ This framework allows both complementarity and conformity or either the special case of $\alpha_{2}=0$ and $\lambda=\alpha_{1}$ (complementarity) or $\alpha_{2}>0$ and $\lambda=\alpha_{2} /\left(1+\alpha_{2}\right)$ (conformity). The vector $\mathbf{e}_{\mathbf{I}}$ marks those in the subset $I$ with ones and zeros elsewhere. Taking the subset, we can define $\mathbf{b}=\left(\mathbf{I}-\lambda \mathbf{G}^{\prime}\right)^{-1} \mathbf{l}$ and note that the overall impact of the shock on this subset is $\tau c \mathbf{b}^{\prime} \mathbf{e}_{\mathbf{I}}=\tau c \sum_{i \in I} b_{i}$. Importantly, the vector $\mathbf{b}$, that we obtain using $\hat{\lambda}$, is the Katz-Bonacich centrality. ${ }^{40}$

From this, Boucher and Fortin (2016) point out that the individuals who will maximize the results of an intervention within a subset are those the most central within this targeted subset. Moreover, the centrality measure depends on a good estimate of $\lambda$ but not on distinguishing between $\alpha_{1}$ or $\alpha_{2}$. These parameters impact the magnitude of the shock not the identity of the core group that will maximize the impact of the shock given the parameters of the underlying model.

To explore this, I first construct the vector $\mathbf{b}$ within a low attitudes subset, where

39. The $\lambda$ condition reflects equilibrium existences. Also, we have $\alpha_{2} \geq 0$ (Boucher and Fortin 2016).

40. This centrality measure takes into account the number of direct and indirect links a person has with less weight given to further away links, in order to provide a measure of one's centrality in the network (Calvó-Armengol, Patacchini, and Zenou 2009). 
I define this as the population in the first two quartiles of the attitudes distribution. Second, I report summary statistics on the key players within this subset for two definitions of key players (KP). The first restricts the key players to the adolescents in the low attitudes subset and within the top two quartiles of Katz-Bonacich centrality given by $\mathbf{b}$. The second repeats this but restricts the key player definition to those within the top quartile of centrality. I report the mean differences between non-KP and KP across my control variable set and measures of parental expectations and investments used for the school-grade peer parental measures defined in section 2.2.

In either definition of key players, a clear pattern stands out. These adolescents are more disadvantaged in terms of their environments than others. They have parents with lower education, more likely to be from single-parent homes, and experience lower parental educational expectations and investments. The general pattern paints a picture of disadvantaged adolescents who are also highly central in their networks. The overall suggestion is that interventions can achieve the largest impact on attitudes by targeting well connected adolescents who have poorer attitudes and who likely lack outside of school investments.

This pattern suggests peer networks can magnify determinants of inequality. For example, disadvantaged children are more likely to have lower parental investments in a high inequality society, because poor local environments and low parental skill increases the parental effort cost of making investments (Doepke and Zilibotti 2017; Doepke, Sorrenti, and Zilibotti 2019). Moreover, with high inequality these disadvantaged families likely face tighter budget constraints further limiting investments. Where their children are highly connected in a social-network the affects of this disadvantage can pass on through complementaries or create norms.

The norms story may be especially salient, as high inequality may also lead to greater segregation (Doepke, Sorrenti, and Zilibotti 2019). Greater segregation, in turn, implies a stronger clustering of children in schools with similar disadvantage. This would suggest that among highly connected individuals there may be less mixing of low and high attitudes, due to very similar outside inputs, that then creates a strong norm within the network.

\section{Results: Peers Parents' Moderating Effects}

This section explores mechanisms around the role of parents for network influence. Parental investments are important to the development of noncognitive skills during early childhood (Attanasio 2015; Heckman and Mosso 2014), but less attention has been focused on the parental role in continued development during adolescence. 
Table 6: Low Attitude Key Player Characteristics

\begin{tabular}{|c|c|c|c|c|c|c|}
\hline & \multicolumn{3}{|c|}{ KP Definition 1} & \multicolumn{3}{|c|}{ KP Definition 2} \\
\hline & $\begin{array}{c}\text { Non-KP } \\
\text { Mean / SD }\end{array}$ & $\begin{array}{c}\text { KP } \\
\text { Mean / SD }\end{array}$ & $\begin{array}{l}\text { Mean } \\
\text { Diff. }\end{array}$ & $\begin{array}{c}\text { Non-KP } \\
\text { Mean / SD }\end{array}$ & $\begin{array}{c}\text { KP } \\
\text { Mean / SD }\end{array}$ & $\begin{array}{l}\text { Mean } \\
\text { Diff. }\end{array}$ \\
\hline Highest Parental Edu & $\begin{array}{l}13.847 \\
(2.725)\end{array}$ & $\begin{array}{l}13.117 \\
(2.657)\end{array}$ & $\begin{array}{l}-0.729^{* * *} \\
(0.133)\end{array}$ & $\begin{array}{l}13.765 \\
(2.706)\end{array}$ & $\begin{array}{l}12.960 \\
(2.768)\end{array}$ & $\begin{array}{l}-0.805^{* * *} \\
(0.174)\end{array}$ \\
\hline Single Parent H.H. & $\begin{array}{c}0.244 \\
(0.430)\end{array}$ & $\begin{array}{c}0.305 \\
(0.461)\end{array}$ & $\begin{array}{l}0.061^{* * *} \\
(0.021)\end{array}$ & $\begin{array}{c}0.248 \\
(0.432)\end{array}$ & $\begin{array}{c}0.343 \\
(0.476)\end{array}$ & $\begin{array}{l}0.095^{* * *} \\
(0.028)\end{array}$ \\
\hline Number of Siblings & $\begin{array}{c}1.539 \\
(1.210)\end{array}$ & $\begin{array}{c}1.433 \\
(1.120)\end{array}$ & $\begin{array}{l}-0.106^{*} \\
(0.058)\end{array}$ & $\begin{array}{c}1.529 \\
(1.193)\end{array}$ & $\begin{array}{c}1.401 \\
(1.156)\end{array}$ & $\begin{array}{l}-0.128^{*} \\
(0.076)\end{array}$ \\
\hline Female & $\begin{array}{c}0.502 \\
(0.500)\end{array}$ & $\begin{array}{c}0.468 \\
(0.499)\end{array}$ & $\begin{array}{l}-0.035 \\
(0.025)\end{array}$ & $\begin{array}{c}0.494 \\
(0.500)\end{array}$ & $\begin{array}{c}0.495 \\
(0.501)\end{array}$ & $\begin{array}{c}0.001 \\
(0.032)\end{array}$ \\
\hline Hispanic & $\begin{array}{c}0.176 \\
(0.381)\end{array}$ & $\begin{array}{c}0.199 \\
(0.399)\end{array}$ & $\begin{array}{c}0.022 \\
(0.019)\end{array}$ & $\begin{array}{c}0.172 \\
(0.377)\end{array}$ & $\begin{array}{c}0.253 \\
(0.435)\end{array}$ & $\begin{array}{l}0.081^{* * *} \\
(0.025)\end{array}$ \\
\hline Black & $\begin{array}{c}0.116 \\
(0.320)\end{array}$ & $\begin{array}{c}0.123 \\
(0.328)\end{array}$ & $\begin{array}{c}0.007 \\
(0.016)\end{array}$ & $\begin{array}{c}0.110 \\
(0.313)\end{array}$ & $\begin{array}{c}0.173 \\
(0.379)\end{array}$ & $\begin{array}{l}0.063^{* * *} \\
(0.021)\end{array}$ \\
\hline Other & $\begin{array}{c}0.179 \\
(0.383)\end{array}$ & $\begin{array}{c}0.132 \\
(0.339)\end{array}$ & $\begin{array}{l}-0.047^{* *} \\
(0.018)\end{array}$ & $\begin{array}{c}0.172 \\
(0.378)\end{array}$ & $\begin{array}{c}0.130 \\
(0.337)\end{array}$ & $\begin{array}{l}-0.042^{*} \\
(0.024)\end{array}$ \\
\hline White & $\begin{array}{c}0.529 \\
(0.499)\end{array}$ & $\begin{array}{c}0.545 \\
(0.498)\end{array}$ & $\begin{array}{c}0.016 \\
(0.024)\end{array}$ & $\begin{array}{c}0.546 \\
(0.498)\end{array}$ & $\begin{array}{c}0.440 \\
(0.497)\end{array}$ & $\begin{array}{l}-0.106^{* * *} \\
(0.032)\end{array}$ \\
\hline Grade 7 & $\begin{array}{c}0.073 \\
(0.261)\end{array}$ & $\begin{array}{c}0.058 \\
(0.234)\end{array}$ & $\begin{array}{l}-0.016 \\
(0.012)\end{array}$ & $\begin{array}{c}0.070 \\
(0.255)\end{array}$ & $\begin{array}{c}0.069 \\
(0.253)\end{array}$ & $\begin{array}{l}-0.001 \\
(0.016)\end{array}$ \\
\hline Grade 8 & $\begin{array}{c}0.082 \\
(0.275)\end{array}$ & $\begin{array}{c}0.040 \\
(0.195)\end{array}$ & $\begin{array}{l}-0.043^{* * *} \\
(0.013)\end{array}$ & $\begin{array}{c}0.077 \\
(0.267)\end{array}$ & $\begin{array}{c}0.032 \\
(0.178)\end{array}$ & $\begin{array}{l}-0.045^{* * *} \\
(0.017)\end{array}$ \\
\hline Grade 9 & $\begin{array}{c}0.137 \\
(0.344)\end{array}$ & $\begin{array}{c}0.116 \\
(0.320)\end{array}$ & $\begin{array}{l}-0.022 \\
(0.017)\end{array}$ & $\begin{array}{c}0.141 \\
(0.348)\end{array}$ & $\begin{array}{c}0.065 \\
(0.247)\end{array}$ & $\begin{array}{l}-0.076^{* * *} \\
(0.022)\end{array}$ \\
\hline Grade 10 & $\begin{array}{c}0.265 \\
(0.441)\end{array}$ & $\begin{array}{c}0.292 \\
(0.455)\end{array}$ & $\begin{array}{c}0.028 \\
(0.022)\end{array}$ & $\begin{array}{c}0.266 \\
(0.442)\end{array}$ & $\begin{array}{c}0.314 \\
(0.465)\end{array}$ & $\begin{array}{c}0.048^{*} \\
(0.029)\end{array}$ \\
\hline Grade 11 & $\begin{array}{c}0.245 \\
(0.431)\end{array}$ & $\begin{array}{c}0.291 \\
(0.454)\end{array}$ & $0.045^{* *}$ & $\begin{array}{c}0.251 \\
(0.434)\end{array}$ & $\begin{array}{c}0.296 \\
(0.457)\end{array}$ & $\begin{array}{c}0.045 \\
(0.028)\end{array}$ \\
\hline Grade 12 & $\begin{array}{c}0.197 \\
(0.398)\end{array}$ & $\begin{array}{c}0.204 \\
(0.403)\end{array}$ & $\begin{array}{c}0.007 \\
(0.020)\end{array}$ & $\begin{array}{c}0.195 \\
(0.396)\end{array}$ & $\begin{array}{c}0.224 \\
(0.418)\end{array}$ & $\begin{array}{c}0.029 \\
(0.026)\end{array}$ \\
\hline Pic Voc Test Scores & $\begin{array}{c}0.143 \\
(0.942)\end{array}$ & $\begin{array}{c}0.087 \\
(0.929)\end{array}$ & $\begin{array}{l}-0.057 \\
(0.046)\end{array}$ & $\begin{array}{c}0.157 \\
(0.933)\end{array}$ & $\begin{array}{c}-0.066 \\
(0.959)\end{array}$ & $\begin{array}{l}-0.223^{* * *} \\
(0.060)\end{array}$ \\
\hline Parental Expectations & $\begin{array}{c}0.091 \\
(0.951)\end{array}$ & $\begin{array}{l}-0.101 \\
(1.032)\end{array}$ & $\begin{array}{l}-0.192^{* * *} \\
(0.048)\end{array}$ & $\begin{array}{c}0.062 \\
(0.969)\end{array}$ & $\begin{array}{l}-0.087 \\
(1.009)\end{array}$ & $\begin{array}{l}-0.149^{* *} \\
(0.063)\end{array}$ \\
\hline Maternal Expectations & $\begin{array}{c}0.099 \\
(0.933)\end{array}$ & $\begin{array}{l}-0.125 \\
(1.047)\end{array}$ & $\begin{array}{l}-0.224^{* * *} \\
(0.049)\end{array}$ & $\begin{array}{c}0.064 \\
(0.960)\end{array}$ & $\begin{array}{l}-0.107 \\
(1.009)\end{array}$ & $\begin{array}{l}-0.171^{* * *} \\
(0.064)\end{array}$ \\
\hline Parental Investments & $\begin{array}{c}0.107 \\
(1.001)\end{array}$ & $\begin{array}{c}-0.094 \\
(0.966)\end{array}$ & $\begin{array}{l}-0.201^{* * * *} \\
(0.049)\end{array}$ & $\begin{array}{c}0.071 \\
(0.991)\end{array}$ & $\begin{array}{c}-0.043 \\
(1.023)\end{array}$ & $\begin{array}{l}-0.113^{*} \\
(0.064)\end{array}$ \\
\hline Maternal Investments & $\begin{array}{c}0.092 \\
(1.003)\end{array}$ & $\begin{array}{c}-0.080 \\
(0.957)\end{array}$ & $\begin{array}{l}-0.172^{* * *} \\
(0.050)\end{array}$ & $\begin{array}{c}0.062 \\
(0.995)\end{array}$ & $\begin{array}{c}-0.041 \\
(0.983)\end{array}$ & $\begin{array}{l}-0.102 \\
(0.066)\end{array}$ \\
\hline $\mathrm{N}$ & 1662 & 554 & & 1939 & 277 & \\
\hline
\end{tabular}

However, disentangling the effect of parents from unobservables is complex and experimental, or quasi-experimental, variation in own-parents' behavior with adolescent friendship networks may not be readily available. Thus, I focus on the school-grade cohort leave-one-out averages of parental expectations and investments.

I specifically explore whether these shifts may moderate the effect of friends on attitudes. I focus on the school-grade cohort level for two reasons. One, to avoid more relevant groupings for friendship connections, as an aim to avoid variation 
that may significantly shift network formation. Two, if the underlying model is one of norms instead of complementaries, then we know that broad shifts in attitudes may be required in order to shift norms and indirectly effect all students through social influence. Thus, a focus on parenting shifts at the cohort-level may capture such broader shifts that a more precise level may not. To set some intuition around potential mechanisms for the role of cohort parenting shifts, consider two cases. One, the network $(\mathbf{G})$ remains fixed. Two, it does not.

In the fixed case, a number of possible channels can generate moderation of the network effect. An increase in average parenting expectations or investments in the cohort, implies some adolescents in the cohort now have greater exposure to increased parental inputs. Suppose, in the extreme, that their attitudes are no longer influenced by friends. Thus, their presence in the network, with direct and indirect links to others, reduces the correlation in attitudes across the network. This would imply a negative effect on an interaction term between cohort peers parenting and friend attitudes. ${ }^{41}$

Another explanation may work through substitution. Where norms best represent the underlying model of social influence, then greater parental expectations or investments in the cohort may enforce the saliency of an aggregate cohort norm and reduce the saliency of norms within small, individual friend groups. Again, this would lead to a negative effect on the interaction term.

In either case, if we do observe a moderating effect, we should observe a positive link between cohort parenting and cohort attitudes even if there is no link with average attitudes in friendship groups. Moreover, for these mechanisms to work average cohort parenting need not have a direct effect on attitudes. ${ }^{42}$ Although, in the substitution story, we may expect that it would, because an adolescent's attention is being diverted to an aggregate norm that cohort parenting may proxy. ${ }^{43}$

In the second case, cohort parenting effects may work through shifting network formation. Suppose increases in expectations and involvement cause these parents to exert greater influence on their adolescent's choice of friends, implying friends with better attitudes. Thus, cohort peers parents can impact individual attitudes through shifting network links. While moderating influence may still exist as above, in this

41. This also suggests, all else equal, that cohort attitudes rise on average, assuming that in the homes where parental expectations or involvement rise there is an increase in own-attitudes.

42. This does not mean that own-parents parenting does not have a direct effect, rather that peers' parents parenting need not have a direct effect to the individual.

43. Cohort parenting may also work through own-parents effort. The direction is not clear, depending on whether it acts as a complement or substitute to own-parental effort. Alternatively, individual parents may not directly (or only weakly) respond to parenting at the cohort-level if they tend to respond primarily to a group most similar to them (e.g. parental peer effects). 
case we would expect to see increases in average attitudes within friend groups even if direct or moderating effects on attitudes do not exist.

Identification is based on within school and across cohort variation. These measures are as good as randomly assigned conditional on parental selection into schools based on fixed school factors that are captured by the school fixed effect (Hoxby 2000). ${ }^{44}$ In table C2, I report balancing tests for the peers' parent variables over adolescent characteristics. If selection effects have been removed, then we should not find a correlation between these variables conditional on school fixed effects and grade-level indicators. In almost all cases, I find highly consistent evidence with this assumption. Most estimates are near zero and insignificant. ${ }^{45}$

Based on the within school, across cohort variation, the peers' parents' variables are independent of unobservable factors determining attitudes. Further, I instrument the moderating effect on friend attitudes with the interaction between the peers' parents' variable and my instrument for friends $\left(\mathbf{G}^{2} P E D U\right)$. For identification of the moderating effect to hold, the interaction between cohort parents' actions and the instrument needs to both be relevant and excludable.

A threat to excludability lies in cohort parenting effects on network formation. Cohort parenting, own-parental education, and friend average parental education are always included as controls. ${ }^{46}$ These will capture variation due to influence on network formation, assuming cohort parents' impact on attitudes through network formation is adequately captured at the mean. Or, under an assumption that any heterogeneous effects from cohort parenting around parents' education on network formation are captured by own- and friend parental education. Nevertheless, interpretation follows under the caution of these assumptions.

In table 7, I report coefficient estimates for the specification in equation 2 adding the peers' parent, and own-parent, variables. Each column header denotes the expectation or involvement variables that have been included. ${ }^{47}$ The effect at the mean for the peers' parents' expectations and involvement is always near zero and only significant in the case of the peers' parents' involvement scale. This is consistent with the results in Bifulco, Fletcher, and Ross (2011), who find that school-grade peers' parental education is not related to immediate adolescent outcomes and attitudes.

44. A relatively large literature has now taken advantage of this argument to estimate peer effects over a wide range of outcomes. See Sacerdote (2014) for a review.

45. Only the correlation between peers' parental involvement and parental education returns a weakly significant result, but one that is small in magnitude. Moreover, all other peers' parents measures are unrelated to parental education.

46. Parental education and friend average education controls are important because the instrument is defined by education of second-order link parents in the network.

47. Friend attitudes is still instrumented with $\mathbf{G}^{2} P E D U$. 
There appears to be very little relation between the school-grade cohorts parental expectations and involvement and attitudes. Next, I turn attention to whether shifts in cohort peers' parents' parenting might interact with network effects.

Table 7: Friend Attitudes and School-Grade Peers' Parents: Level Effects

\begin{tabular}{lcccc}
\hline $\begin{array}{c}(1) \\
\text { D.V. Attitudes }\end{array}$ & $\begin{array}{c}\text { Parental } \\
\text { Expectations }\end{array}$ & $\begin{array}{c}(2) \\
\text { Maternal } \\
\text { Expectations }\end{array}$ & $\begin{array}{c}(3) \\
\text { Maternal } \\
\text { Involvement }\end{array}$ & $\begin{array}{c}(4) \\
\text { Parental } \\
\text { Involvement }\end{array}$ \\
\hline Friend Attitudes & $0.546^{*}$ & $0.519^{*}$ & $0.588^{* *}$ & $0.593^{* *}$ \\
& $(0.309)$ & $(0.307)$ & $(0.282)$ & $(0.294)$ \\
SG Parent & 0.012 & 0.015 & 0.023 & $0.039^{* *}$ \\
& $(0.020)$ & $(0.024)$ & $(0.024)$ & $(0.020)$ \\
Parent Variable & $0.134^{* * *}$ & $0.169^{* * *}$ & $0.151^{* * *}$ & $0.162^{* * *}$ \\
& $(0.032)$ & $(0.031)$ & $(0.027)$ & $(0.027)$ \\
\hline $\mathrm{N}$ & 2216 & 2216 & 2216 & 2216 \\
\hline Note: $*$ p < 0.1, ** p < 0.05, *** p < 0.01. N=2216. Standard errors clustered at the school-grade level \\
are in parentheses. All specifications include the baseline own and friend controls and school fixed effects. \\
The dependent variable (D..) is always attitudes. Column headers denote the parent variable in use for \\
that specification. School-grade (SG) peer leave-one-out means of the parent variable are denoted by SG \\
Parent and where missing these are set to the mean and a missing indicator controlled for. The model is \\
2SLS with friend attitudes instrumented by $\mathbf{G}^{2} P E D U$.
\end{tabular}

In table 8, I report the results from interacting the school-grade leave-one-out mean of cohort peers' parents' expectations and involvement with friend attitudes. I also report the main effect of these measures and the own-parent level of the parenting variable as a control. ${ }^{48}$ In panel $\mathrm{A}$, the model is just identified, using as instruments $\mathrm{G}^{2} P E D U$ and it's interaction with the peers' parent' variable listed in the column header. In panel B, I supplement the IV set with additional interactions between $\mathbf{G}^{2} P E D U$ and the school-grade leave-one-out means of female and race/ethnicity measures. ${ }^{49}$

The results suggest parental expectations drive moderating effects but not involvement. First, in all cases the friend attitude level effect is strong and significant. Second, the interaction effect is strong and significant only for cohort peers' parents' expectations or peers' maternal expectations. For the involvement measures the interaction effect is negative but very close to zero. It appears that parental expectations within a school-grade cohort strongly diminish network influences. Turing to panel B, I again find the same pattern and estimates that are highly similar to panel A. Also, in all cases these specifications easily pass the over-identification test.

48. The specification corresponds to the baseline specification reported in column 4 of table 2 but with the interaction between GY and the peers' parents variable of interest, a control for the peers' parents main effect, and a control for the own-parent level. For avoidance of confusion, the cohort peers' parents is the leave one out mean of expectations or involvement defined at an adolescent's same school grade level. Own-parent represents information for the individual adolescent's parents.

49. Estimation for panel B specifications is by two-step GMM. 
Table 8: Friend Attitudes and School-Grade Peers' Parents: Interaction Effect

\begin{tabular}{|c|c|c|c|c|}
\hline $\begin{array}{l}\text { D.V. } \\
\quad=\text { Attitudes }\end{array}$ & $\begin{array}{c}(1) \\
\text { Parental } \\
\text { Expectations }\end{array}$ & $\begin{array}{c}(2) \\
\text { Maternal } \\
\text { Expectations }\end{array}$ & $\begin{array}{c}(3) \\
\text { Maternal } \\
\text { Involvement }\end{array}$ & $\begin{array}{c}(4) \\
\text { Parental } \\
\text { Involvement }\end{array}$ \\
\hline \multicolumn{5}{|l|}{ Panel A: Just-Identified } \\
\hline Friend Attitudes (GY) & $\begin{array}{l}0.665^{* *} \\
(0.333)\end{array}$ & $\begin{array}{l}0.680^{* *} \\
(0.297)\end{array}$ & $\begin{array}{l}0.584^{* *} \\
(0.282)\end{array}$ & $\begin{array}{l}0.581^{* *} \\
(0.293)\end{array}$ \\
\hline $\begin{array}{l}\text { Friend Attitudes } \\
\text { X SG Parent }\end{array}$ & $\begin{array}{l}-0.304^{* *} \\
(0.144)\end{array}$ & $\begin{array}{l}-0.392^{* *} \\
(0.176)\end{array}$ & $\begin{array}{l}-0.023 \\
(0.187)\end{array}$ & $\begin{array}{l}-0.066 \\
(0.178)\end{array}$ \\
\hline SG Parent & & & & \\
\hline Parent Variable & $\begin{array}{l}0.117^{* * *} \\
(0.028)\end{array}$ & $\begin{array}{l}0.147^{* * *} \\
(0.030)\end{array}$ & $\begin{array}{l}0.152^{* * * *} \\
(0.028)\end{array}$ & $\begin{array}{l}0.163^{* * *} \\
(0.027)\end{array}$ \\
\hline $\mathrm{KP}-\mathrm{F}$ & 7.028 & 12.700 & 9.582 & 9.915 \\
\hline \multicolumn{5}{|l|}{ Panel B: Multiple IVs } \\
\hline Friend Attitudes (GY) & $\begin{array}{l}0.966^{* * *} \\
(0.201)\end{array}$ & $\begin{array}{l}0.833^{* * *} \\
(0.186)\end{array}$ & $\begin{array}{l}0.896^{* * *} \\
(0.196)\end{array}$ & $\begin{array}{l}0.871^{* * *} \\
(0.200)\end{array}$ \\
\hline $\begin{array}{l}\text { Friend Attitudes } \\
\text { X SG Parent }\end{array}$ & $\begin{array}{l}-0.323^{* * *} \\
(0.124)\end{array}$ & $\begin{array}{l}-0.355^{* *} \\
(0.158)\end{array}$ & $\begin{array}{l}-0.133 \\
(0.143)\end{array}$ & $\begin{array}{l}-0.166 \\
(0.126)\end{array}$ \\
\hline SG Parent & $0.193^{* *}$ & $0.166^{*}$ & 0.091 & 0.135 \\
\hline Parent Variable & $\begin{array}{l}(0.077) \\
0.111^{* * *} \\
(0.020)\end{array}$ & $\begin{array}{l}(0.090) \\
0.156^{* * * *} \\
(0.025)\end{array}$ & $\begin{array}{l}(0.087) \\
0.146^{* * *} \\
(0.025)\end{array}$ & $\begin{array}{l}(0.091) \\
0.147 * * * \\
(0.023)\end{array}$ \\
\hline $\mathrm{KP}-\mathrm{F}$ & 8.188 & 8.648 & 6.078 & 6.487 \\
\hline Over-ID P-Value & 0.555 & 0.459 & 0.441 & 0.503 \\
\hline
\end{tabular}

To provide some context to these results, consider a shift in cohort maternal educational expectations. For example, on average if mean maternal expectations in a school grade cohort are increased from the $25^{\text {th }}$ to the $75^{\text {th }}$ percentile, then the marginal effect of friends' attitudes falls by $40 \%$ from 0.89 to 0.53 . In the case of an even more drastic shift from the $10^{\text {th }}$ to the $90^{\text {th }}$ percentile, it falls by approximately $68 \%$ from 1 to $0.32 .{ }^{50}$

For the level effect from cohort parenting, only cohort parental (and maternal) expectations have a direct significant relationship with attitudes. ${ }^{51}$ Moreover, the

50. Percentiles of Cohort Mean Maternal Expectations (Index Values): $10^{\text {th }} \approx-0.83 ; 25^{\text {th }} \approx$ $-0.53 ; 75^{\text {th }} \approx 0.39 ; 90^{\text {th }} \approx 0.93$.

51. Measures of own-parental expectations and involvement are also positively related to attitudes; however, these are likely endogenous thus I include them only as controls and drop them in robustness checks reported in table I1. 
extent of this effect is considerably stronger where mean attitudes amongst friends in the network are quite low. For example, holding mean friend attitudes at the $25^{\text {th }}$ percentile, a shift of cohort mean maternal expectations from the $25^{\text {th }}$ to the $75^{\text {th }}$ percentile returns an approximate $27 \%$ of a standard deviation increase in the mean of adolescent attitudes. Conversely, for the same shift in cohort maternal expectations but holding friend attitudes at the $75^{\text {th }}$ percentile, mean adolescent attitudes actually decrease by approximately $6 \%$ of a standard deviation. Where friend attitudes are already high, it appears there is some crowding out of effects, but where attitudes amongst friend groups are low, there appear to be sizable gains from treatments that are able to substantially shift parental expectations.

I examine a number of robustness checks in the appendix table I1. In panel A of table I1, I drop the likely endogenous own-parent variable from the control set. The results remain highly consistent with those of table 8. In panel B, I add controls for school-grade leave-one-out means of attitudes, parental education, single parent homes, the number of siblings in the home, female, and race/ethnicity. If the exclusion restriction is violated by other potential channels through the school-grade cohort, then I expect the interaction effect estimates to be quite sensitive. They are not. Peers' parental expectations are strongly linked with moderating effects on the influence of friend attitudes.

Another point is that shifts in cohort parenting may shift friend attitudes. The previous discussion of results assumes fixed mean friend attitudes. As noted previously, this could represent a threat to identification. However, beyond this if increases in cohort parenting improve mean friend attitudes, then it could also represent a mechanism whereby cohort parenting exerts an influence on individual adolescent attitudes.

In table 9, I look for suggestive evidence around how shifts in cohort peers'-peers defined by sharing the same school and grade - parental expectations and involvement shift average attitudes within different categories of peer groups. First, I regress average friend attitudes on cohort peers' parents' expectations and involvement and the baseline set of controls, friend controls, and school fixed effects. Cohort peers' parenting is mostly unrelated to average friend attitudes. Only cohort peers' parental involvement has a weak, positive correlation with friend attitudes.

Second, I regress average school-grade cohort peer attitudes on the same specification. Here, cohort peers' parenting exhibits a stronger correlation, especially for expectations. The aggregate attitudes in an adolescent's school-grade cohort are increasing in that cohort's parents' expectations (marginally so for involvement). For parental expectations, where moderating effects appear present, cohort attitudes 
press upwards. This is expected where the mechanisms discussed previously create moderating effects. In either the protection or substitution story, improved parenting in a cohort raises the attitudes amongst enough of the cohort to mitigate network effects and press cohort peers' attitudes higher. This is consistent with a story that cohort parenting choices can moderate the effects of small friend groups even if not directly affecting network formation.

For cohort parental involvement, however, we observe a different pattern: limited direct effects, no moderating effects, but some evidence for positive mean shifts in friend group attitudes. ${ }^{52}$ This is at least suggestive that in some cases cohort parenting may also shift network formation thereby indirectly influencing adolescents through peer effects.

In the last row, I turn to the more refined SGRGR peer group, which is potentially more salient for friend selection. Here, the same school-grade cohort parenting variables are unrelated to SGRGR peers' attitudes. This is also reassuring for the exclusion restriction when SGRGR attitudes are used as an instrument for friend attitudes. If school-grade level peers' parenting is related to attitudes, then we might be worried it also correlates with the refined SGRGR group. However, there is no correlation, which in general is in-line with the results on friend attitudes. This further suggests that the larger cohort moderating effect does not work through a direct shift in the attitudes of relevant peers (e.g. SGRGR) or imply friends with better attitudes. ${ }^{53}$

These results imply that on average the school-grade cohort is improving in attitudes as cohort parenting improves. Also, for expectations, this is unrelated to friend attitudes. While I cannot completely untangle the underlying mechanism, a potential explanation for the moderating effect on cohort expectations is that of norm transmission (Akerlof and Kranton 2000, 2002; Bisin et al. 2011).

Higher effort by more parents in a cohort to transmit educational expectations may shift attention from friend group attitudes to norms defined more broadly in the school. The subsequent effect is to moderate friend influence. This is at least consistent with the model of norms and the potential for the important source of social influence to vary between local (friends) and global (cohort) groups. Further, it suggests interventions may be able to shift the focus of norms from friends' attitudes

52. The effect of cohort parental involvement on friend attitudes is only weakly significant. Conclusions are suggestive and cautious.

53. Since I use second-order links parental education as the primary instrument, I also have regressed this instrument on the school-grade peers' parents' parenting variables, the parent's own-parenting, and the baseline controls and school fixed effects. I find no correlation between the instrument and any of the peers' parenting variables. Changes in aggregate cohort parental expectations and involvement are not related to second-order links parental education. 
Table 9: Peer Attitudes: The Effect of School-Grade Peers' Parents

\begin{tabular}{|c|c|c|c|c|}
\hline & $\begin{array}{c}(1) \\
\text { Parental } \\
\text { Expectations }\end{array}$ & $\begin{array}{c}(2) \\
\text { Maternal } \\
\text { Expectations }\end{array}$ & $\begin{array}{c}(3) \\
\text { Maternal } \\
\text { Involvement }\end{array}$ & $\begin{array}{c}(4) \\
\text { Parental } \\
\text { Involvement }\end{array}$ \\
\hline \multicolumn{5}{|c|}{$\begin{array}{l}\text { Panel A: Friends' } \\
\text { Attitudes }\end{array}$} \\
\hline SG Parent & $\begin{array}{c}0.009 \\
(0.021)\end{array}$ & $\begin{array}{c}0.024 \\
(0.026)\end{array}$ & $\begin{array}{c}0.039 \\
(0.025)\end{array}$ & $\begin{array}{c}0.043^{*} \\
(0.023)\end{array}$ \\
\hline \multicolumn{5}{|c|}{$\begin{array}{l}\text { Panel B: School-Grade } \\
\text { Peers' Attitudes }\end{array}$} \\
\hline SG Parent & $\begin{array}{l}0.043^{* *} \\
(0.020)\end{array}$ & $\begin{array}{l}0.053^{* *} \\
(0.025)\end{array}$ & $\begin{array}{c}0.007 \\
(0.019)\end{array}$ & $\begin{array}{c}0.037^{*} \\
(0.022)\end{array}$ \\
\hline \multicolumn{5}{|c|}{$\begin{array}{r}\text { Panel B: } S G R G R \\
\text { Peers } \\
\text { Attitudes }\end{array}$} \\
\hline SG Parent & $\begin{array}{c}0.030 \\
(0.023)\end{array}$ & $\begin{array}{c}0.047 \\
(0.028)\end{array}$ & $\begin{array}{c}0.009 \\
(0.030)\end{array}$ & $\begin{array}{c}0.022 \\
(0.031)\end{array}$ \\
\hline
\end{tabular}

to elsewhere by shifting expectations amongst cohort parents. Alternatively, for cohort parental investments, there is suggestive evidence that the main mechanism of influence may be through shifting friend groups toward better attitudes.

\section{Conclusion}

Peer influence at school has long been a concern for parents of adolescents along with whether they can remain effective in protecting their teenagers from bad influence. Skills and beliefs remain malleable during adolescence. One particular area bad influence may create long-term consequences is by impacting the development of these skills and beliefs. Educational attitudes are important in their own right. They have long-term implications for educational attainment (Lipnevich, Gjicali, and Krumm 2016), and in general, noncognitive skills have a causal impact on many long-term outcomes (Heckman and Mosso 2014).

Social ties outside of the home become more important during adolescence (Bagwell and Schmidt 2013; Mak, Fosco, and Feinberg 2018), and the combination of friend and parent influence may be important to development. In economic theory, groups with the strongest influence relate to the groups most relevant to a person's identity and with whom one shares the greatest identity investments (Akerlof and Kranton 2000, 2002; Bénabou and Tirole 2011). In that regard, close friends and 
parents are likely the most relevant relationships to explore for conforming influences that shape adolescent attitudes.

In this paper, I have focused on a component of noncognitive skills, attitudes about school and future education, and on the relationship between an adolescent and their friends' attitudes. Furthermore, I explored whether school-grade cohort peers' parents' educational expectations and involvement can moderate the influence of friends on attitudes. The results imply friendship circles can influence the formation of attitudes, that this result is highly robust to a wide range of sensitivity checks, and that it is nonlinear such that friends with the worst attitudes exert stronger marginal effects. Also, I find that peers' parents' expectations can reduce the overall influence friends exert despite not necessarily improving the attitudes of direct friends.

There is still much to discover about the processes shaping skills during adolescence. Attitudes represent only one component of a broad set of skills and beliefs that are malleable. The point at which these skills become set is also unknown, with current research implicitly suggesting that at some point it is too late to intervene (Sampson 2016).

In this study, I show that friends are important for the development of attitudes about school during adolescence. As social identity and social ties become increasingly important during the adolescent years, successful interventions will need to take networks into account. Finally, I show that school-grade peers' parents may serve as one channel to diminish network influence, potentially by shifting the focus of educational norms within the cohort. Early childhood interventions are highly important, but so too may be adolescent interventions targeted on the right mechanisms.

\section{References}

Advani, Arun, and Bansi Malde. 2018. "Credibly Identifying Social Effects: Accounting for Network Formation and Measurement Error." Journal of Economic Surveys. IS S N: 1467-6419. doi:10.1111/joes.12256.

Akerlof, George. 1997. "Social Distance and Social Decisions." Econometrica : Journal of the Econometric Society 65 (5): 1005-1027.

Akerlof, George, and Rachel Kranton. 2000. "Economics and Identity." The Quarterly Journal of Economics 115 (3): 715-753.

2002. "Identity and schooling: some lessons for the economics of education." Journal of Economic Literature 40 (4). 
Anelli, Massimo, and Giovanni Peri. 2016. "The effects of high school peers' gender on college major, college performance and income." The Economic Journal. doi:10.1111/ecoj.12556.

Attanasio, Orazio. 2015. "The Determinants of Human Capital Formation During the Early Years of Life: Theory, Measurement, and Policies." Journal of the European Economic Association 13 (6): 949-997.

Attanasio, Orazio, Sarah Cattan, Emla Fitzsimons, Costas Meghir, and Marta RubioCodina. 2015. Estimating the Production Function for Human Capital: Results from a Randomized Control Trial in Colombia. Working Paper, Working Paper Series 20965. National Bureau of Economic Research. doi:10.3386/w20965. http://www.nber.org/papers/w20965.

Avvisati, Francesco, Marc Gurgand, Nina Guyon, and Eric Maurin. 2014. "Getting Parents Involved: A Field Experiment in Deprived Schools." The Review of Economic Studies 81 (1): 57-83.

Badev, Anton. 2013. "Discrete Games in Endogenous Networks: Theory and Policy," no. 45. https: / / repository . upenn. edu / cgi / viewcontent. cgi ? article $=1044 \&$ context $=$ psc_working_papers.

Bagwell, Catherine, and Michelle Schmidt. 2013. Friendships in Childhood and Adolescence. Guilford Press.

Becker, Gary S. 1994. "Human Capital Revisited." In Human Capital: A Theoretical and Empirical Analysis with Special Reference to Education, 3rd Edition, 15-28. The University of Chicago Press.

Bénabou, Roland, and Jean Tirole. 2011. "Identity, morals, and taboos: Beliefs as assets." The Quarterly Journal of Economics 126 (2): 805-855.

Bifulco, Robert, Jason M. Fletcher, and Stephen L. Ross. 2011. "The Effect of Classmate Characteristics on Post-Secondary Outcomes: Evidence from the Add Health." American Journal: Economic Policy 3 (1): 25-53.

Bifulco, Robert, Jason Fletcher, Sun Jung Oh, and Stephen Ross. 2014. "Do high school peers have persistent effects on college attainment and other life outcomes?" Labour Economics 29:83-90. 
Bisin, Alberto, Eleonora Patacchini, Thierry Verdier, and Yves Zenou. 2011. "Formation and persistence of oppositional identities." European Economic Review $55(8)$.

Black, Sandra, Paul Devereux, and Kjell Salvanes. 2013. "Under pressure? The effect of peers on outcomes of young adults." Journal of Labor Economics 31 (1): 119-153.

Bono, Emilia Del, Marco Francesconi, Yvonne Kelly, and Amanda Sacker. 2016. "Early Maternal Time Investment and Early Child Outcomes." The Economic Journal 126 (596).

Boucher, Vicent, and Bernard Fortin. 2016. "Some Challenges in the Empirics of the Effects of Networks." In The Oxford Handbook of the Economics of Networks, 277-302.

Bramoullé, Yann, Habiba Djebbari, and Bernard Fortin. 2009. "Identification of Peer Effects Through Social Networks." Journal of Econometrics 150 (1): 41-55.

Caeyers, Bet, and Marcel Fafchamps. 2016. "Exclusion Bias in the Estimation of Peer Effects," no. w22565.

Calvó-Armengol, Antoni, Eleonora Patacchini, and Yves Zenou. 2009. "Peer Effects and Social Networks in Education." The Review of Economic Studies 76 (4): $1239-1267$.

Carrell, Scott E., Mark Hoekstra, and Elira Kuka. 2018. "The Long-Run Effects of Disruptive Peers." American Economic Review 108 (11): 3377-3415.

Chetverikov, Denis, Dongwoo Kim, and Daniel Wilhelm. 2018. "Nonparametric instrumental-variable estimation." Stata Journal 18 (4): 937-950.

Cunha, Flavio, and James J. Heckman. 2008. "Formulating, Identifying and Estimating the Technology of Cognitive and Noncognitive Skill Formation." Journal of Human Resources 43 (4): 738-782.

Cunha, Flavio, James J. Heckman, and Susanne M Schennach. 2010. "Estimating the Technology of Cognitive and Noncognitive Skill Formation." Econometrica 78 (3): 883 .

Deming, David. 2017. "The Growing Importance of Social Skills in the Labor Market." The Quarterly Journal of Economics 132 (4): 1593-1640. 
Doepke, Matthias, Giuseppe Sorrenti, and Fabrizio Zilibotti. 2019. "The Economics of Parenting." Annual Review of Economics 11 (1). doi:10.1146/annureveconomics-080218-030156.

Doepke, Matthias, and Fabrizio Zilibotti. 2017. "Parenting with Style: Altruism and Paternalism in Intergenerational Preference Transmission." Econometrica 85 (5): 1331-1371.

Fiorini, Mario, and Michael Keane. 2014. "How the Allocation of Children's Time Affects Cognitive and Noncognitive Development." Journal of Labor Economics 32 (4): 787-836.

Fortin, Bernard, and Myra Yazbeck. 2015. "Peer Effects, Fast Food Consumption and Adolescent Weight Gain." Journal of Health Economics 42 (42): 125-138.

Fruehwirth, Jane. 2016. "Your Peers' Parents: Understanding Classroom Spillovers from Parental Education through Teaching Practices, Parental Involvement and Skill." https://sites.google.com/site/janecooleyfruehwirth/research.

Fruehwirth, Jane Cooley, Sriya Iyer, and Anwen Zhang. 2018. "Religion and Depression in Adolescence." Forthcoming, Journal of Political Economy.

Goldsmith-Pinkham, Paul, and Guido W. Imbens. 2013. "Social Networks and the Identification of Peer Effects." Journal of Business 8 Economic Statistics 31 (3): 253-264.

Graham, Bryan. 2015. "Methods of Identification in Social Networks." Annual Review of Economics 7 (1): 465-485.

. 2016. "Homophily and transitivity in dynamic network formation." No. w22186. National Bureau of Economic Research. doi:10.3386/w22186.

—. 2017. "An econometric model of network formation with degree heterogeneity." Econometrica 85 (4): 1033-1063.

Griffith, Alan. 2019. "Name Your Friends, but Only Five? The Importance of Censoring in Peer Effects Estimates using Social Network Data." Working Paper. https://sites.google.com/site/alangriffithecon/research.

Heckman, James J., John Eric Humphries, and Tim Kautz. 2014. The Myth of Achievement Tests: The GED and the Role of Character in American Life. University of Chicago Press. 
Heckman, James, and Stefano Mosso. 2014. "The Economics of Human Development and Social Mobility." Annual Review of Economics 6 (1): 689-733.

Henderson, Daniel, and Anne-Charlotte Souto. 2018. "An Introduction to Nonparametric Regression for Labor Economists." Journal of Labor Research 39 (4): $355-382$.

Horowitz, Joel. 2011. "Applied Nonparametric Instrumental Variables Estimation." Econometrica 79 (2): 347-394.

Hoxby, Caroline M. 2000. "Peer Effects in the Classroom: Learning from Gender and Race Variation." Working Paper.

Hsieh, Chih-Sheng, and Lung-fei Lee. 2016. "A Social Interactions Model with Endogenous Friendship Formation and Selectivity." Journal of Applied Econometrics 31 (2): 301-319.

Jackson, Matthew O. 2011. "Chapter 12 - An Overview of Social Networks and Economic Applications*," edited by Alberto Bisin Jess Benhabib and Matthew O. Jackson, 1:511-585. Handbook of Social Economics. North-Holland.

Johnsson, Ida, and Hyungsik Roger Moon. 2017. "Estimation of Peer Effects in Endogneous Social Networks: Control Function Approach." ArXiv preprint. arXiv:1709.10024.

Koch, Alexander, Julia Nafziger, and Helena Skyt Nielsen. 2015. "Behavioral Economics of Education." Journal of Economic Behavior \&f Organization 115:3-17. doi:10.1016/j.jebo.2014.09.005.

Lavy, Victor, and Analia Schlosser. 2011. "Mechanisms and impacts of gender peer effects at school." American Economic Journal: Applied Economics 3 (2): 1-33.

Lewbel, Arthur, Xi Qu, and Xun Tang. 2019. "Social Networks with Misclassified or Unobserved Links." Working Paper. https://economics-events.sydney.edu. au / wp- content / uploads / 2019 / 08 / Social - Networks - with- Misclassified - or Unobserved-Links.pdf.

Lin, Xu. 2010. "Identifying peer effects in student academic achievement by spatial autoregressive models with group unobservables." Journal of Labor Economics 28 (4): 825-860. 
Lin, Xu. 2015. "Utilizing Spatial Autoregressive Models to Identify Peer Effects Among Adolescents." Empirical Economics 49 (3): 929-960.

Lipnevich, Anastasiya, Kalina Gjicali, and Stefan Krumm. 2016. "Understanding Attitudes in Education: New Directions for Assessment." In Non-cognitive Skills and Factors in Educational Attainment, edited by Myint Swe Khine and Shaljan Areepattamannil, 31-64. Rotterdam: SensePublishers. I S B N: 978-94-6300-591-3. doi:10.1007/978-94-6300-591-3_3.

Liu, Xiaodong, Eleonora Patacchini, and Yves Zenou. 2014. "Endogenous Peer Effects: Local Aggregate or Local Average?" Journal of Economic Behavior 86 Organization 103:39-59.

Liu, Xiaodong, Eleonora Patacchini, Yves Zenou, and Lung-Fei Leek. 2014. "Criminal Networks: Who is the Key Player?" Working Paper. https://intranet.royalholl oway.ac.uk/economics/documents/pdf/staffseminars/yveszenoucriminalnetw orks, whoisthekeyplayer.pdf.

Mak, Hio, Gregory Fosco, and Mark Feinberg. 2018. "The role of family for youth friendships: Examining a social anxiety mechanism." Journal of youth and adolescence 47 (2): 306-320.

Manski, Charles F. 1993. "Identification of Endogenous Social Effects: The Reflection Problem." The Review of Economic Studies 60 (3): 531-542.

Norris, Jonathan. 2019. "Identity economics: Social Influence and Skill Development." Journal of Economic Surveys 33 (5): 1389-1408.

Olivetti, Claudia, Eleonora Patacchini, and Yves Zenou. 2018. "Mothers, Peers, and Gender-Role Identity." Journal of the European Economic Association.

Patachini, Eleonora, Edoardo Rainone, and Yves Zenou. 2016. "Heterogenous Peer Effects in Education." Journal of Economic Behavior \& Organization 134:190227.

Sacerdote, Bruce. 2014. "Experimental and Quasi-Experimental Analysis of Peer Effects: Two Steps Forward?" Annual Review of Economics 6 (1): 253-272.

Sampson, Robert J. 2016. "The Characterological Imperative: On Heckman, Humphries, and Kautz's The Myth of Achievement Tests: The GED and the Role of Character in American Life." Journal of Economic Literature 54 (2): 493-513. 
Wooldridge, Jeffrey. 2007. "What's New in Econometrics? Lecture 6: Control Functions and Related Methods." NBER. http://www.nber.org/WNE/lect_6_ controlfuncs.pdf.

2015. "Control Function Methods in Applied Econometrics." Journal of Human Resources 50 (2): 420-445.

Zhang, Shiyu, Laura Baams, Daphne Bongardt, and Judith Dubas. 2018. "Intra-and inter-individual differences in adolescent depressive mood: The role of relationships with parents and friends." Journal of abnormal child psychology 46 (4): 811-824. 


\section{Appendix: Supplementary Materials}

\section{A Details on the Sample and Variable Construction}

Table A1 compares the in-home survey saturated school sample with the inhome, non-saturated school sample. Missing observations in these variables have been removed in both samples. Mean differences are calculated from a regression of each variable on an indicator that flags observations belonging to the saturated sample. While the mean differences are often statistically significant, they are in general small and suggest the samples are quite similar.

Table A1: Comparison Between Saturated and Non-Saturated Sample

\begin{tabular}{|c|c|c|c|}
\hline & $\begin{array}{c}\text { Saturated Sample } \\
\text { Mean / SD }\end{array}$ & $\begin{array}{c}\text { Non-Sat. Sample } \\
\text { Mean / SD }\end{array}$ & $\begin{array}{c}\text { Mean } \\
\text { Differences }\end{array}$ \\
\hline Highest Parental Edu & $\begin{array}{l}13.547 \\
(2.742)\end{array}$ & $\begin{array}{l}13.723 \\
(2.813)\end{array}$ & $\begin{array}{l}-0.176^{* * *} \\
(0.055)\end{array}$ \\
\hline Single Parent H.H. & $\begin{array}{c}0.274 \\
(0.446)\end{array}$ & $\begin{array}{c}0.324 \\
(0.468)\end{array}$ & $\begin{array}{l}-0.050^{* * * *} \\
(0.009)\end{array}$ \\
\hline Number of Siblings & $\begin{array}{l}1.493 \\
(1.209)\end{array}$ & $\begin{array}{l}1.465 \\
(1.201)\end{array}$ & $\begin{array}{c}0.028 \\
(0.023)\end{array}$ \\
\hline Female & $\begin{array}{l}0.497 \\
(0.500)\end{array}$ & $\begin{array}{l}0.509 \\
(0.500)\end{array}$ & $\begin{array}{l}-0.012 \\
(0.010)\end{array}$ \\
\hline Hispanic & $\begin{array}{c}0.198 \\
(0.399)\end{array}$ & $\begin{array}{c}0.157 \\
(0.364)\end{array}$ & $\begin{array}{l}0.041^{* * *} \\
(0.007)\end{array}$ \\
\hline Black & $\begin{array}{c}0.151 \\
(0.358)\end{array}$ & $\begin{array}{c}0.228 \\
(0.420)\end{array}$ & $\begin{array}{l}-0.077^{* * *} \\
(0.008)\end{array}$ \\
\hline Other & $\begin{array}{c}0.150 \\
(0.357)\end{array}$ & $\begin{array}{c}0.068 \\
(0.252)\end{array}$ & $\begin{array}{l}0.082^{* * *} \\
(0.005)\end{array}$ \\
\hline White & $\begin{array}{c}0.500 \\
(0.500)\end{array}$ & $\begin{array}{c}0.547 \\
(0.498)\end{array}$ & $\begin{array}{l}-0.046^{* * *} \\
(0.010)\end{array}$ \\
\hline Grade 7 & $\begin{array}{c}0.077 \\
(0.267)\end{array}$ & $\begin{array}{c}0.143 \\
(0.351)\end{array}$ & $\begin{array}{l}-0.066^{* * *} \\
(0.007)\end{array}$ \\
\hline Grade 8 & $\begin{array}{c}0.085 \\
(0.279)\end{array}$ & $\begin{array}{c}0.146 \\
(0.353)\end{array}$ & $\begin{array}{l}-0.061^{* * *} \\
(0.007)\end{array}$ \\
\hline Grade 9 & $\begin{array}{c}0.111 \\
(0.314)\end{array}$ & $\begin{array}{c}0.197 \\
(0.397)\end{array}$ & $\begin{array}{l}-0.086^{* * *} \\
(0.007)\end{array}$ \\
\hline Grade 10 & $\begin{array}{c}0.267 \\
(0.442)\end{array}$ & $\begin{array}{c}0.185 \\
(0.388)\end{array}$ & $\begin{array}{l}0.082^{* * *} \\
(0.008)\end{array}$ \\
\hline Grade 11 & $\begin{array}{c}0.250 \\
(0.433)\end{array}$ & $\begin{array}{c}0.180 \\
(0.384)\end{array}$ & $\begin{array}{l}0.071^{* * *} \\
(0.008)\end{array}$ \\
\hline Grade 12 & $\begin{array}{c}0.210 \\
(0.407)\end{array}$ & $\begin{array}{c}0.149 \\
(0.356)\end{array}$ & $\begin{array}{l}0.061^{* * *} \\
(0.007)\end{array}$ \\
\hline Attitudes & $\begin{array}{l}-0.030 \\
(1.002)\end{array}$ & $\begin{array}{c}0.030 \\
(0.987)\end{array}$ & $\begin{array}{l}-0.060^{* * *} \\
(0.019)\end{array}$ \\
\hline Pic Voc Test Scores & $\begin{array}{c}0.015 \\
(0.899)\end{array}$ & $\begin{array}{c}0.058 \\
(0.980)\end{array}$ & $\begin{array}{l}-0.043^{* *} \\
(0.019)\end{array}$ \\
\hline $\mathrm{N}$ & 3222 & 14393 & \\
\hline
\end{tabular}

Attitudes about school is constructed as an index normalized to mean zero and a standard deviation of one using factor analysis. A set of scale-type questions related to how much a respondent reports a desire to go to college, how likely they think it 
is they will go to college, whether they feel apart of their current school, are happy at their current school, feel that their teachers are fair, and feel close to people at their school forms the index. Tables A2 and A3 contain summary statistics and information on the factor analysis. The factor analysis is conducted on the full sample post-listwise deletion of missing observations in the measures included for the factor analysis. Table A2 shows that all of the variables range from one to five. The scales are coded such that ones relate to the lowest report for a variable and fives the highest.

Table A2: Summary Statistics for Attitudes Measures

\begin{tabular}{lccccccc}
\hline & \multicolumn{3}{c}{ Pre-listwise Deletion } & & \multicolumn{3}{c}{ Sample for Factor Analysis } \\
\cline { 2 - 3 } & Mean & SD & N & & Mean & SD & N \\
\hline Desire for College & 4.30 & 1.13 & 3683 & & 4.30 & 1.12 & 3596 \\
How Likely College & 4.00 & 1.23 & 3680 & & 4.01 & 1.22 & 3596 \\
Feel Part of School & 3.81 & 1.04 & 3611 & & 3.81 & 1.04 & 3596 \\
Happy to be at School & 3.71 & 1.09 & 3613 & & 3.71 & 1.09 & 3596 \\
Feel Teachers are Fair & 3.52 & 1.05 & 3613 & & 3.52 & 1.05 & 3596 \\
Feel Close to People at School & 3.73 & 1.00 & 3613 & & 3.73 & 1.00 & 3596 \\
\hline
\end{tabular}

Note: Each measure 1-5 ranking with 1 the lowest and 5 the highest.

Table A3 shows that the factor loadings for all measures load strongly onto a single factor. Only one factor in the analysis has an eigenvalue greater than one - the common cut-off rule for considering a factor as potentially relevant. The second factor, reported in column 2, is close to the cut-off and thus worth mentioning. It appears to load more heavily on the desire for and belief in going to college than the remaining measures. However, this second factor explains much less of the shared variation in the measures than the first factor and no other factor is remotely close to either of these. Finally, the first factor loads relatively evenly, and strongly, across the measures, with the exception of feeling teachers are fair, suggesting it better captures how these measures jointly relate. The interest of this study is to recognize the importance of attitudes that are difficult to measure but that the noncognitive literature suggest may be malleable and important. Thus, I focus on the first factor. Overall, the factor analysis points strongly toward these measures explaining an underlying latent factor that I will call attitudes. I next explore whether this attitudes variable relates to later life education in a reasonable manner.

I explore the association between the attitudes index formed from the first factor loadings and later life educational attainment. I draw educational attainment from wave IV of the data when the respondents ranged in age from 25-33. Figure A1 shows the distribution of the attitudes index at education level. There is clear pattern of the distribution of attitudes in high school shifting right at higher levels of eventual 
Table A3: Results of Factor Analysis on Attitudes Measures

\begin{tabular}{|c|c|c|}
\hline \multirow[b]{2}{*}{ Measures } & \multicolumn{2}{|c|}{ Factor Loadings } \\
\hline & (1) & $(2)$ \\
\hline Desire for College & 0.532 & 0.583 \\
\hline How Likely College & 0.537 & 0.580 \\
\hline Feel Part of School & 0.681 & -0.292 \\
\hline Happy to be at School & 0.616 & -0.289 \\
\hline Feel Teachers are Fair & 0.356 & -0.189 \\
\hline Feel Close to People at School & 0.579 & -0.307 \\
\hline Eigenvalues & 1.876 & 0.975 \\
\hline Proportion of & & \\
\hline Variance Explained & 0.801 & 0.416 \\
\hline
\end{tabular}

education. We see that high school dropouts exhibit the worst attitudes, high school diploma holders tend towards the average, and those with at least some college or better tend towards more positive attitudes. These patterns are also consistent with the literature on noncognitive skills and later life outcomes. Those with generally better noncognitive skills tend to outperform those with lower skills Heckman and Mosso 2014.

In table A4, I report results from examining the association between attitudes and years of completed education. These are not causal. In a descriptive sense, if these attitudes measures are meaningful then the attitudes index should be strongly related to eventual attainment. I report the results with and without the primary controls used in this study plus age at wave IV and with and without school fixed effects. In the last specification, I also include the Add Health Peabody Picture Vocabulary (AH PVT) test scores as a proxy for ability.

The association between attitudes and years of education on average is on the order of a half-year for a standard deviation increase on the attitudes scale. This association reduces slightly to about 0.43 once including the controls in column 2 but does not change thereafter. In general, the attitudes index formed from the measures described previously links strongly with later life education. This is both consistent with the expectation of this study and with the broader noncognitive skill literature. 


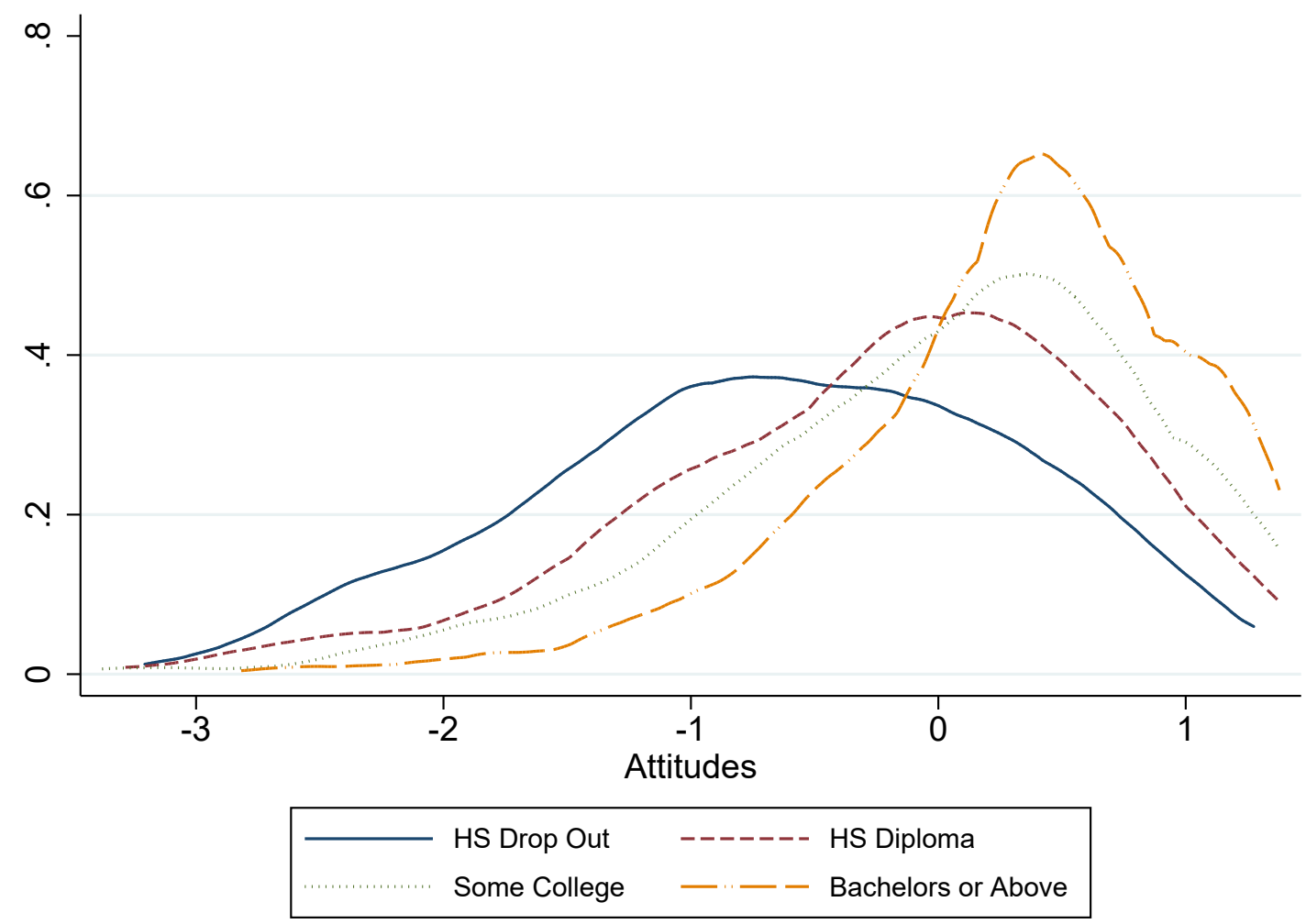

Figure A1: Empirical Attitudes by Wave IV Education Level

Table A4: Completed Years of Education at Wave IV and Attitudes from High School

\begin{tabular}{lcccc}
\hline & $(1)$ & $(2)$ & $(3)$ & $(4)$ \\
\hline Attitudes & $0.531^{* * *}$ & $0.428^{* * *}$ & $0.428^{* * *}$ & $0.414^{* * *}$ \\
& $(0.034)$ & $(0.033)$ & $(0.033)$ & $(0.033)$ \\
AH PVT & & & & $0.438^{* * *}$ \\
& & & Yes & Yes \\
Controls & No & Yes & Yes & Yes \\
School Fixed Effects & No & No & 2807 & 2807 \\
$\mathrm{~N}$ & 2807 & 2807 & 0.245 & 0.278 \\
$R^{2}$ & 0.132 & 0.245 & 0.245 \\
\hline
\end{tabular}

Note: $* \mathrm{p}<0.1,{ }^{* *} \mathrm{p}<0.05,{ }^{* * *} \mathrm{p}<0.01$. Robust standard errors are in parentheses. The dependent variables is years of education as of wave IV when respondents range in age from 25-33. The control set is the same as that used in the main analyses plus age at wave IV. Observations missing values for control variables are imputed to the mean if continuous or to 0 if discrete and a missing indicator is included among the controls. This is also true for the inclusion of the Add Health Peabody Picture Vocabulary (AH PVT) scores in column 4. Sixty eight observations missing an attitudes score are dropped. The remaining lost observations are from sample attrition. 


\section{B Construction of Parental Variables}

Table B1: Summary Statistics for Parental Measures

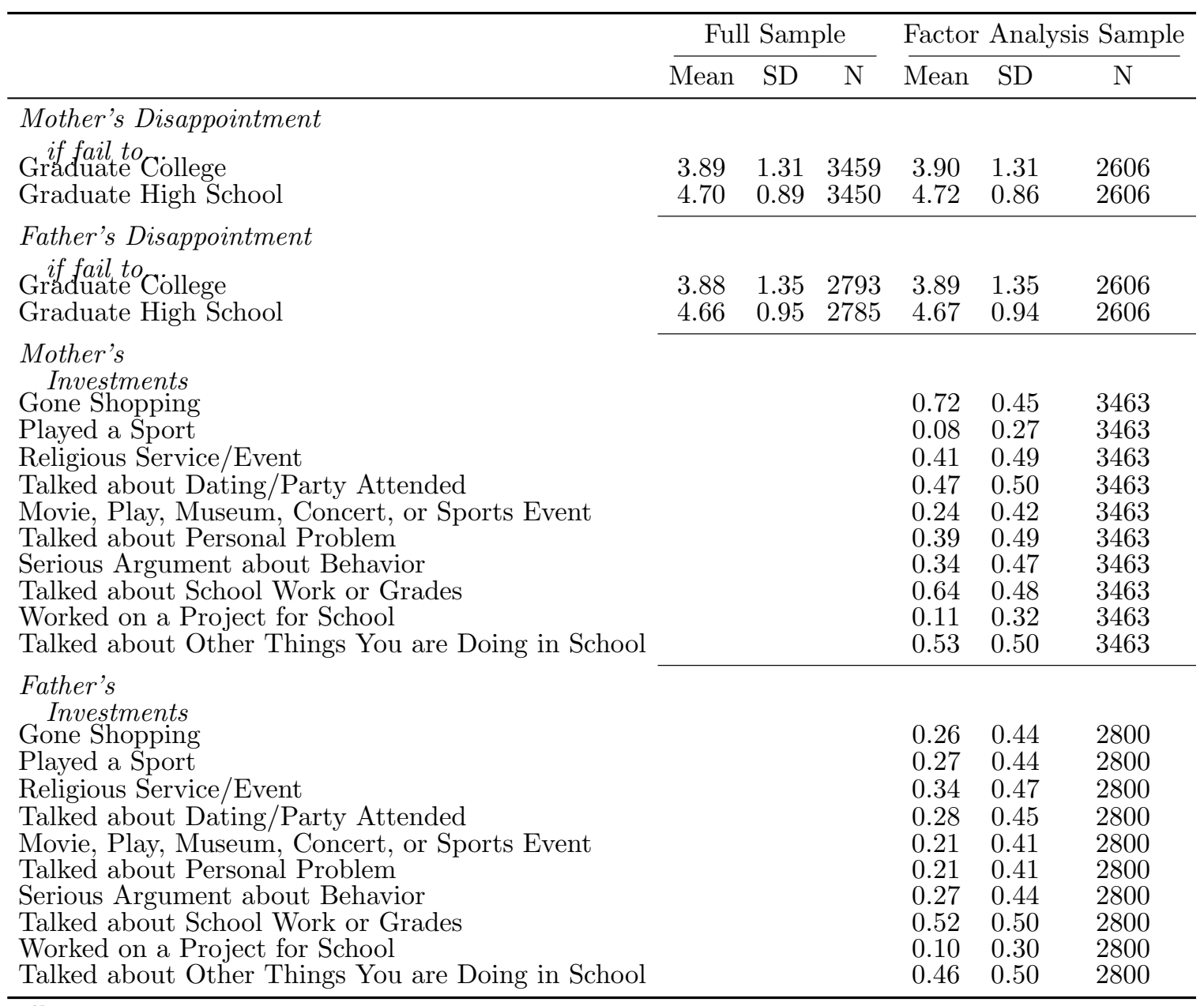

Note: The disappointment measures are used in the factor analysis for parental expectations. These measures are ranked 1-5 with 1 the lowest and 5 the highest. The investment variables are binary (yes, no). 
Table B2: Results of Factor Analysis on Parental Measures

\begin{tabular}{|c|c|c|}
\hline & \multicolumn{2}{|c|}{ Factor Loadings } \\
\hline & Mother & Father \\
\hline \multicolumn{3}{|l|}{$\begin{array}{l}\text { Disappointment } \\
\text { if fail to... }\end{array}$} \\
\hline Graduate College & 0.737 & 0.753 \\
\hline Graduate High School & 0.698 & 0.736 \\
\hline Eigenvalue & \multicolumn{2}{|c|}{2.138} \\
\hline Proportion of Variance Explained & \multicolumn{2}{|c|}{0.887} \\
\hline \multicolumn{3}{|l|}{ Investments } \\
\hline Gone Shopping & 0.436 & 0.421 \\
\hline Played a Sport & 0.379 & 0.428 \\
\hline Religious Service/Event & 0.227 & 0.287 \\
\hline Talked about Dating/Party Attended & 0.399 & 0.461 \\
\hline Movie, Play, Museum, Concert, or Sports Event & 0.478 & 0.464 \\
\hline Talked about Personal Problem & 0.499 & 0.520 \\
\hline Serious Argument about Behavior & 0.192 & 0.173 \\
\hline Talked about School Work or Grades & 0.691 & 0.670 \\
\hline Worked on a Project for School & 0.650 & 0.677 \\
\hline Talked about Other Things You are Doing in School & 0.704 & 0.714 \\
\hline Eigenvalue & 2.454 & 2.589 \\
\hline Proportion of Variance Explained & 0.829 & 0.850 \\
\hline \multicolumn{3}{|c|}{$\begin{array}{l}\text { Note: Factor analysis for the disappointment (expectations) measures uses mother and father measures } \\
\text { together. The expectations scale uses the predicted factor based on these loadings. To avoid lost obser- } \\
\text { vations, I generate the scale for mothers and fathers separately using the predicted factor scores, then I } \\
\text { take the average of the mother and father expectations scale if both are non-missing or only the mother } \\
\text { if the father's scale is missing and vice-versa. For the involvement measures, I run the factor analysis } \\
\text { separately on the mother's and father's measures. Because these are binary, I use the polychoric correla- } \\
\text { tion matrix from the involvement measures to run the factor analysis. To form the parental involvement } \\
\text { scale, I first generate the predicted factor for mothers and fathers based on their loadings. Second, I take } \\
\text { the average of these two scales if both are non-missing or take the mother's scale if the father is missing } \\
\text { and vice-versa. }\end{array}$} \\
\hline
\end{tabular}

Table B3: Summary Statistics for Parent Variables

\begin{tabular}{|c|c|c|c|c|c|c|c|}
\hline & \multicolumn{3}{|c|}{$\begin{array}{c}\text { Full } \\
\text { Sample }\end{array}$} & \multicolumn{3}{|c|}{$\begin{array}{l}\text { Selected } \\
\text { Sample }\end{array}$} & \multirow{2}{*}{$\begin{array}{c}\text { P-Value } \\
\text { Mean Diff. }\end{array}$} \\
\hline & Mean & $\mathrm{SD}$ & $\mathrm{N}$ & Mean & SD & $\mathrm{N}$ & \\
\hline SG Parental Expectations & 0.010 & $(0.228)$ & 3523 & 0.013 & $(0.197)$ & 2205 & 0.291 \\
\hline SG Maternal College Expectations & 0.003 & $(0.287)$ & 3363 & 0.006 & $(0.237)$ & 2099 & 0.480 \\
\hline SG Parental Investments & 0.013 & $(0.176)$ & 3543 & 0.019 & $(0.162)$ & 2216 & 0.011 \\
\hline SG Maternal Investments & 0.011 & $(0.166)$ & 3367 & 0.012 & $(0.143)$ & 2099 & 0.886 \\
\hline
\end{tabular}




\section{Balancing Tests}

Table C1: Instrument Balancing Tests

\begin{tabular}{|c|c|c|c|c|c|c|c|c|}
\hline Panel A & $\begin{array}{l}\text { Single } \\
\text { Parent }\end{array}$ & $\begin{array}{c}\text { Num. } \\
\text { Siblings }\end{array}$ & Female & Hispanic & Black & Other & \multicolumn{2}{|l|}{ AHPVT } \\
\hline $\mathrm{G}^{2} \mathrm{PEDU}$ & 0.017 & -0.020 & -0.004 & $-0.011^{* *}$ & $0.008 *$ & $0.005 * *$ & \multicolumn{2}{|l|}{ * 0.015} \\
\hline PEDU & $\begin{array}{c}(0.011) \\
\text { Yes }\end{array}$ & $\begin{array}{c}(0.015) \\
\text { Yes }\end{array}$ & $\begin{array}{c}(0.005) \\
\text { Yes }\end{array}$ & $\begin{array}{c}(0.005) \\
\text { Yes }\end{array}$ & $\begin{array}{c}(0.004) \\
\text { Yes }\end{array}$ & $\begin{array}{c}(0.002) \\
\text { Yes }\end{array}$ & \multicolumn{2}{|l|}{$(0.011)$} \\
\hline Friend Controls & Yes & Yes & Yes & Yes & Yes & Yes & \multicolumn{2}{|l|}{ Yes } \\
\hline $\mathrm{N}$ & 2216 & 2216 & 2216 & 2216 & 2216 & 2216 & \multicolumn{2}{|l|}{2216} \\
\hline \multirow[b]{2}{*}{ Panel B } & \multicolumn{4}{|c|}{ Own Characteristics } & \multicolumn{4}{|c|}{ Average of Friends } \\
\hline & $\begin{array}{l}\text { Single } \\
\text { Parent }\end{array}$ & $\begin{array}{l}\text { Num. } \\
\text { Siblings }\end{array}$ & AHPVT & $\begin{array}{c}\text { Highest } \\
\text { PEDU }\end{array}$ & $\begin{array}{l}\text { Single } \\
\text { Parent }\end{array}$ & $\begin{array}{l}\text { Num. } \\
\text { Siblings }\end{array}$ & AHPVT & $\begin{array}{c}\text { Highest } \\
\text { PEDU }\end{array}$ \\
\hline SGRGR Attitudes & -0.027 & 0.070 & 0.052 & -0.154 & 0.025 & -0.037 & -0.024 & -0.000 \\
\hline & $(0.032)$ & $(0.068)$ & $(0.036)$ & $(0.184)$ & $(0.017)$ & $(0.038)$ & $(0.036)$ & $(0.000)$ \\
\hline Own Characteristics & Yes & Yes & Yes & Yes & Yes & Yes & Yes & Yes \\
\hline Friend Characteristics & Yes & Yes & Yes & Yes & Yes & Yes & Yes & Yes \\
\hline $\mathrm{N}$ & 2005 & 2005 & 2005 & 2005 & 2005 & 2005 & 2005 & 2005 \\
\hline
\end{tabular}




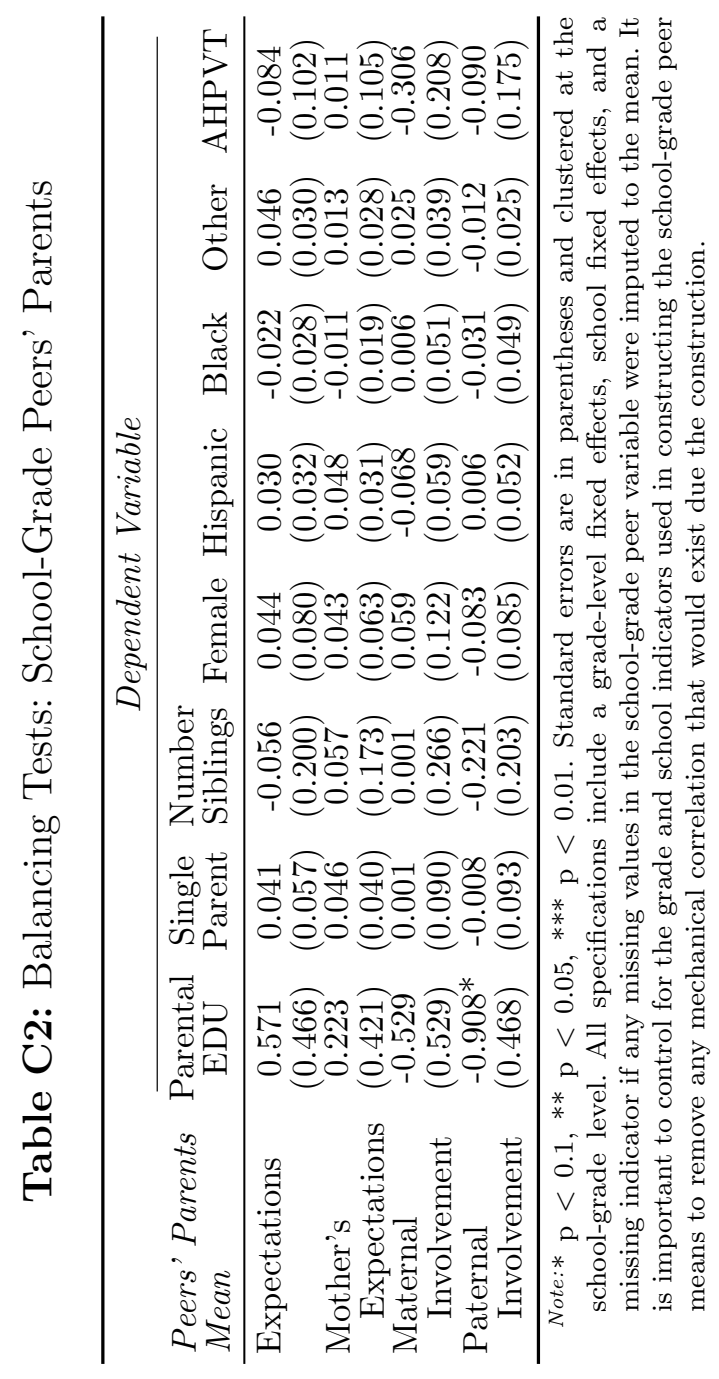




\section{Semi-Parametric Control Function Approach with En- dogenous Network Formation}

The instrument matrix is $\mathbf{Z}=\left[\mathbf{X} \mathbf{G X} \mathbf{G}^{2} \mathbf{X}\right] \cdot{ }^{54}$ For $\mathbf{Z}$ to be a valid instrument matrix, the assumption that $\mathbb{E}\left[\mathbf{Z}^{\prime} \epsilon\right]=0$ must hold. However, as noted section previously, unobserved characteristics that impact network formation and outcomes will correlate $\mathbf{G}$ with $\epsilon$ violating this assumption. Johnsson and Moon (2017) approach aims to restore the validity of $\mathbf{G}^{2} \mathbf{X}$ as instruments for the simultaneity that are free of selection bias.

Links form between adolescent dyads following

$$
D_{i j, N}=\mathbb{1}\left(T_{i j}^{\prime} \gamma+A_{i}+A_{j}-u_{i j} \geq 0\right)
$$

$D_{i j, N}$ takes the value of 1 if a link exists for the i,jth dyad and 0 otherwise. $T_{i j}$ represents a matrix of $t_{i j}=\left|x_{i}-x_{j}\right|$ variables that capture the difference between each of the observable characteristics of each adolescent in the dyad. Every variable in $\mathbf{X}$ can be included here, but as will be described below the set had to be restricted for some schools. $\gamma$ is the coefficient vector for homophily taste in friend selection and $\gamma<0$ implies a taste for homophily in link formation for the observable covariates. In a slight abuse of notation, redefining $n$ and $N$, there are $n=\left(\begin{array}{c}N \\ 2\end{array}\right)$ dyads, where $N$ is the number of observations in a network. ${ }^{55} u_{i j}$ is an idiosyncratic shock, and it is assumed that $u_{i j} \perp(\mathbf{X}, \mathbf{A}, \epsilon) .{ }^{56}$

$A_{i}$ and $A_{j}$ generate endogeneity between dyad unobserved heterogeneity in link formation and outcomes. An important contribution of Graham (2017) is the development of estimation techniques for this model, allowing the unobserved heterogeneity to be of arbitrary correlation rather than the stronger restriction of random effects in Goldsmith-Pinkham and Imbens (2013). This model of network formation does not admit interdependence based on network structure (e.g. transitivity: impact of shared links on linking decision). Graham $(2015,2017)$ show that with a single observation of the network we cannot identify network structure covariates in the link formation model including unobserved heterogeneity, as both homophily and transitivity lead to clusters. ${ }^{57}$ What we can do is estimate network formation con-

54. One can restrict $\mathbf{G}^{2} \mathbf{X}$ to a subset of $\mathbf{X}$ as needed for the purpose of instrument strength.

55. This model applies to a single network, thus I will run the model for each school separately and then stack up the results for $\hat{A}_{i}$.

56. Johnsson and Moon (2017) assume the undirected graph but the approach is valid for the directed graph as well.

57. A recent development by Graham (2016) provides a method to incorporate both but requires four periods of network observations. 
trolling for homophily and unobserved fixed effects and then obtain an estimate of this unobserved heterogeneity determinant.

An estimate of $A_{i}$ can be used to correct the bias from endogenous network links, if attitudes are influenced by unobservables that also make the adolescent a better or worse linking partner to select. An example case is a student who has traits that make them popular and that also influence attitudes. Higher ability may make a student more or less popular to select based on, for example, whether other students share their ability (homophily), desire to be linked to someone of higher ability, or desires to not be linked with anyone of a particularly high ability. The goal is to obtain $\hat{A}_{i}$ in a first step and control for it in the second using a non-parametric sieve basis - which allows a flexible functional form between $\epsilon$ and $A_{i}$ - in the two stage least square (2SLS) estimation of peer effects. Because the link formation regressors are dyad specific and of a non-linear form, there are natural exclusion restrictions created between the link formation regressors and regressors in the outcome equation. No outside instruments are required.

Estimates of $\hat{A}_{i}$ are obtained from a logit following the joint maximum likelihood estimator developed in Graham (2017) of $D_{i j, N}$ with dyad specific regressors. This particular dyadic model is designed to be run on a single network. I run the network formation model separately by school-network, stack up the estimates of $A_{i}$ from each into a single vector, and then return to the block-diagonal adjacency matrix for the second step. This did require adjusting the indicator covariates by school because some schools, for example, had no observations for Hispanic ethnicity and so on.

Given an estimate for $A_{i}$, Johnsson and Moon (2017) define the $\mathbb{E}\left[\epsilon_{i} \mid A_{i}\right]=h\left(A_{i}\right)$ where $h\left(A_{i}\right)$ is an unknown function to be approximated by a sieve estimator. They consider multiple versions of the sieve estimator of which I adopt the polynomial. ${ }^{58}$ The estimated sieve basis is $\hat{\mathbf{Q}}=\left[\begin{array}{llll}A_{i}^{0} & A_{i}^{1} & \ldots & A_{i}^{K_{N}}\end{array}\right]$, where $K_{N}$ is the degree of the polynomial. I choose $K_{N}=6 .{ }^{59}$ Finally, the outcome equation is rewritten as

$$
\mathbf{Y}=\mathbf{C} \theta+\hat{\mathbf{Q}} \alpha+\epsilon+H(A)-\hat{\mathbf{Q}} \alpha
$$

where $\mathbf{C}=\left[\begin{array}{lll}\mathbf{G Y} & \mathbf{X} & \mathbf{G X}\end{array}\right]$ and $\theta=\left[\begin{array}{lll}\lambda & \beta_{1} & \beta_{2}\end{array}\right]^{\prime}$. Define $M=I-\hat{\mathbf{Q}}\left(\hat{\mathbf{Q}} \hat{\mathbf{Q}}^{-1} \hat{\mathbf{Q}}^{\prime}\right.$ with $I$ the identity matrix. Johnsson and Moon (2017) show that the 2SLS estimator controlling for the fixed effect individual heterogeneity in link formation and restoring

58. I also tested the cosine sieve basis but it did not change the results.

59. Monte carlo results suggest that peer effect estimates are more precise with $K_{N}=6$ (Johnsson and Moon 2017). 
peers of peers characteristics to valid instruments is ${ }^{60}$

$$
\hat{\theta}=\left(\mathbf{C}^{\prime} M \mathbf{Z}\left(\mathbf{Z}^{\prime} M \mathbf{Z}\right)^{-1} \mathbf{Z}^{\prime} M \mathbf{C}\right)^{-1} \mathbf{C} M \mathbf{Z}\left(\mathbf{Z}^{\prime} M \mathbf{Z}^{\prime}\right)^{-1} \mathbf{Z}^{\prime} M \mathbf{Y}
$$

Johnsson and Moon (2017) improve in a number of ways on previous attempts in the literature to handle bias from peer selection. First, they develop an estimator that is more computationally tractable than previous methods. Second, they do not impose a normality assumption in the joint distribution of the errors, rather their approach is flexible. Third, they derive asymptotic results. Furthermore, the network formation model by Graham (2017) allows unobserved heterogeneity in the link formation model of arbitrary correlation, relaxing the stronger random effect restrictions necessary in previous applied studies. Thus, network endogeneity in the model by Johnsson and Moon (2017) is generated by an individual specific fixed effect in the model of friendship choice that is correlated with $\epsilon$ in equation 2. Just as one includes observable covariates to control for homophily bias, estimating and then controlling for this fixed effect captures peer selection bias as far as that bias runs through dyad invariant ${ }^{61}$ unobservables. Absence of a change in the social interaction effect will suggest that the model already adequately controls the friend selection mechanisms.

60. See Johnsson and Moon (2017) for derivation of asymptotic results and formulas for variance estimation.

61. Similar to time-invariant in a panel data context 


\section{E Additional Statistics and Results}

Table E1: First-Stage Results

\begin{tabular}{|c|c|c|c|c|}
\hline & (1) & $(2)$ & $(3)$ & (4) \\
\hline \multicolumn{5}{|l|}{$\mathrm{G}^{2} \mathrm{IVs}$} \\
\hline Parental Edu & $0.069^{* *}$ & * $0.070^{* * *}$ & & $0.065^{* * *}$ \\
\hline Single Parent H.H. & $\begin{array}{l}(0.013) \\
-0.015\end{array}$ & & & \\
\hline & $(0.070)$ & & & \\
\hline Num of Siblings & 0.011 & & & \\
\hline Female & $\begin{array}{c}0.125 \\
(0.078)\end{array}$ & & & \\
\hline Hispanic & 0.073 & & & \\
\hline Black & 0.010 & & & \\
\hline & $(0.191)$ & & & \\
\hline Other & $\begin{array}{c}0.163 \\
(0.194)\end{array}$ & & & \\
\hline School Grade & 0.061 & & & \\
\hline SGRGR Attitudes & $(0.049)$ & & $\begin{array}{l}0.168^{* *} \\
(0.042)\end{array}$ & $\begin{array}{c}* 0.164^{* * *} \\
(0.042)\end{array}$ \\
\hline $\mathrm{N}$ & 2216 & 2216 & 2005 & 2005 \\
\hline
\end{tabular}


Table E2: Summary Statistics for Friend Averages

\begin{tabular}{lcc}
\hline & \multicolumn{2}{c}{ Main } \\
& \multicolumn{2}{c}{ Analysis } \\
\cline { 2 - 3 } & Mean & SD \\
\hline Friends (G) & & \\
Attitudes & 0.179 & 0.718 \\
Highest Parental Edu & 13.740 & 2.248 \\
Single Parent Household & 0.256 & 0.324 \\
Number of Siblings & 1.488 & 0.878 \\
Female & 0.521 & 0.366 \\
Hispanic & 0.180 & 0.358 \\
Black & 0.119 & 0.310 \\
Other & 0.168 & 0.355 \\
White & 0.532 & 0.482 \\
School Grade & 10.187 & 1.365 \\
Pic Voc Test Scores & 0.135 & 0.776 \\
\cline { 2 - 3 } G & & \\
Highest Parental Edu & 13.809 & 1.934 \\
Single Parent Household & 0.260 & 0.258 \\
Number of Siblings & 1.473 & 0.707 \\
Female & 0.533 & 0.284 \\
Hispanic & 0.175 & 0.337 \\
Black & 0.116 & 0.296 \\
Other & 0.173 & 0.346 \\
White & 0.532 & 0.482 \\
School Grade & 10.214 & 1.294 \\
Pic Voc Test Scores & 0.148 & 0.651 \\
\hline Observations & 2216 & \\
& &
\end{tabular}


Table E3: Attitudes and Friend Attitudes: Additional Robustness Checks

\begin{tabular}{lccccccc}
\hline & $(1)$ & $(2)$ & $(3)$ & $(4)$ & $(5)$ & $(6)$ & $(7)$ \\
\hline Friend Attitudes & $0.606^{* * *}$ & $0.590^{* * *}$ & $0.481^{* *}$ & $0.569^{* * *}$ & $0.590^{* *}$ & $0.608^{* * *}$ & $0.593^{* * *}$ \\
& $(0.234)$ & $(0.207)$ & $(0.229)$ & $(0.194)$ & $(0.230)$ & $(0.231)$ & $(0.209)$ \\
Highest Parental Edu & & & $0.025^{* *}$ & $0.025^{* *}$ & $0.023^{* *}$ & $0.057^{* * *}$ \\
& & & $(0.010)$ & $(0.011)$ & $(0.010)$ & $(0.019)$ \\
Neigh. \% 25+ College Degree & & & & & -0.070 & $2.268^{* *}$ & $2.039^{*}$ \\
& & & & & $(0.323)$ & $(1.142)$ & $(1.232)$ \\
Parental Edu & & & & & & $-0.164^{* *}$ & $-0.157^{*}$ \\
Neigh. \% 25+ College Degree & & & & & & $(0.076)$ & $(0.083)$ \\
\hline School-Grade FE & Yes & Yes & No & No & No & No & Yes \\
SGRGR IV & No & Yes & No & Yes & No & No & Yes \\
FoF Controls & No & No & Yes & Yes & No & No & No \\
Census Block-Level Controls & No & No & No & No & Yes & Yes & Yes \\
\hline N & 2216 & 2005 & 2216 & 2005 & 2216 & 2216 & 2005 \\
KP-F & 29.640 & 18.228 & 27.479 & 18.458 & 30.576 & 30.406 & 18.041 \\
Over-ID P-Value & & 0.668 & & 0.817 & & & 0.693 \\
\hline
\end{tabular}

Note: $* \mathrm{p}<0.1,{ }^{* *} \mathrm{p}<0.05,{ }^{* * *} \mathrm{p}<0.01$. Robust standard errors are in parentheses. All specifications include school-fixed effects, except columns 1,2, and 7 . All specifications include the baseline control set and friend controls. FoF controls are the friend-of-friend average controls corresponding to the baseline set of controls minus the IV. Additional neighborhood (census block-level controls) are the block-level unemployment rate and proportion of the population that is white, black, Hispanic (other race), and Asian/Pacific islander. 


\section{F Robustness to Missing Links and Observations}

Here I describe and report two sensitivity checks against potential missing links and missing data. In first, I assume friendship reciprocity and construct the undirected graph. If someone nominates you as a friend, then both that person and you receive a link in the adjacency matrix. As a result, some observations are regained $(N=2977)$ that were dropped because of missing friendship nominations in the directed graph. A concern with the undirected graph is that some links are induced where they do not exist. I report the results for the baseline specifications with the undirected graph in appendix able F1. Overall, these results are highly consistent with the baseline from the directed graph. The 2SLS estimates are relatively larger but their $95 \%$ confidence intervals do overlap with the baseline point estimates in table 2 . That the point estimates inflate when using the undirected graph is not uncommon. Lin (2010, 2015) finds a similar pattern when examining the effect of friends for GPA and a range of risky behaviors. Thus, I continue with the directed graph moving forward.

Table F1: Attitudes and Friends Attitudes: Undirected Network

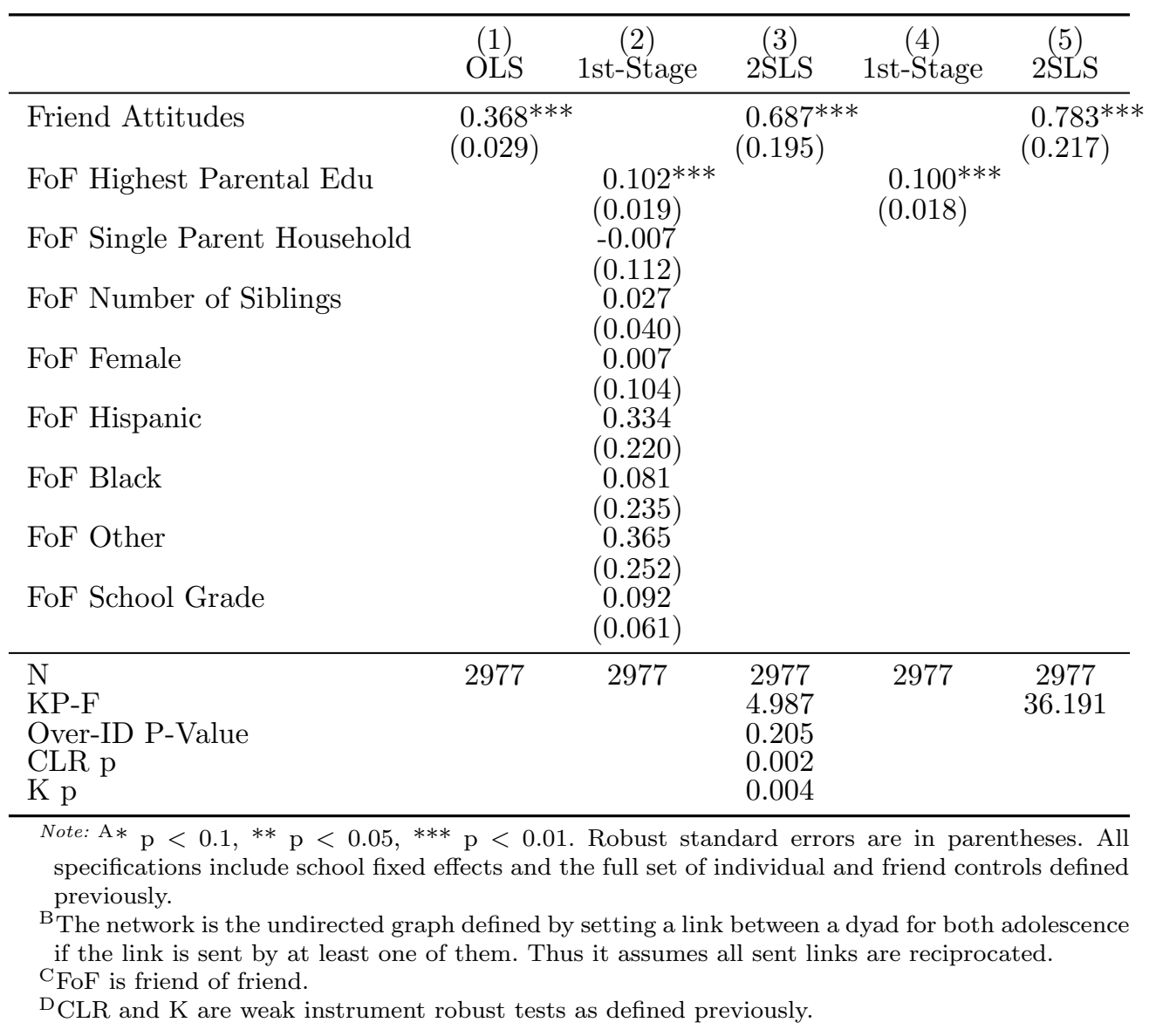

Second, I test against sample selection bias by allowing imputation. I recognize 
that one should be cautious with imputation when using 2SLS and I emphasize that the primary point of the exercise is to check whether the effect sizes remain consistent with the baseline. I consider both multiple imputation and a simpler mean imputation with a missing indicator control. The results are reported in the appendix, table F2. ${ }^{62}$ I first use multiple imputation to impute missing observations in the instrument and friend average variables. ${ }^{63}$ The estimate effect sizes under this approach remain very close to the baseline result.

For the simpler imputation, I continue to drop missing observations from the attitude measures. Otherwise, I set missing values for continuous variables to the mean and to zero for discrete variables. Because, I merge back the observations that are missing onto the selected sample, all observations with any missing values among the friend variables will be missing all their friend variable values, thus I only need a single missing indicator to account for the imputation. I check the results both imputing on the missing controls (dropped in the multiple imputation) and dropping them for consistency with the multiple imputation checks. The results from this simpler imputation are somewhat smaller, near 0.5 , than the baseline results but are still highly consistent. While imputation does not provide a perfect test against bias from lost observations, it suggests that the results are not driven by sample selection issues.

62. With multiple imputation, I first drop missing observations from the attitudes measures and attitudes index. I also drop missing observations in the controls because many of these are binary which is not appropriate for imputation with multivariate normal imputation.

63. I do this both with multivariate normal imputation and second with monotone imputation, which assumes the missing pattern is consistent for all observations in each variable but allows for less restrictive regression imputation. 
Table F2: Check Against Sample Selection Bias: Imputation

\begin{tabular}{|c|c|c|c|}
\hline & $\begin{array}{c}(1) \\
\text { MVN Imputation }\end{array}$ & $\begin{array}{c}(2) \\
\text { Mono Imputation }\end{array}$ & $\begin{array}{c}(3) \\
\text { Simple Imputation }\end{array}$ \\
\hline $\begin{array}{l}\text { Friend Attitudes } \\
\text { miss }\end{array}$ & $\begin{array}{l}0.618^{* *} \\
(0.287)\end{array}$ & $\begin{array}{l}0.659^{* * *} \\
(0.225)\end{array}$ & $\begin{array}{ll}0.475^{* *} & 0.503^{* * *} \\
(0.185) & (0.185) \\
-0.274^{* * *} & -0.270^{* * *} \\
(0.039) & (0.041)\end{array}$ \\
\hline $\begin{array}{l}\mathrm{N} \\
\mathrm{KP}-\mathrm{F}\end{array}$ & $\begin{array}{c}3405 \\
.\end{array}$ & $\begin{array}{c}3405 \\
.\end{array}$ & $\begin{array}{c}3596 \\
45.998\end{array}$ \\
\hline
\end{tabular}

Note: $\mathrm{A} * \mathrm{p}<0.1,{ }^{* *} \mathrm{p}<0.05,{ }^{* * *} \mathrm{p}<0.01$. Estimates are from 2SLS after imputation. Robust standard errors are in parentheses. All specifications include school fixed effects and the full set of individual and friend controls defined previously. The KP-F is not calculated with multiple imputation.

${ }^{\mathrm{B}} \mathrm{MVN}$ is multivariate normal imputation. Mono is monotone imputation which assumes the missing pattern is consistent for all observations in each variable. Mono imputation here is done with regression for each variable with missing data.

${ }^{\mathrm{C}}$ With multiple imputation MVN is not appropriate for missing observations with binary or categorical variables. I drop missing observations in the controls for this reason and focus on imputation for the missing observations in friend variables (these are continuous).

${ }^{D}$ Under simple imputation I set missing observations for a variable to the mean if continuous or 0 otherwise and control for a missing indicator.

ESample size is reduced from 3702 by dropping missing observations in the attitudes variables and the individual controls (but keep the missing observations in friend average variables). In column 3, with simple substitution I keep missing observations from individual controls and set them to 0 if missing. 


\section{G Nonparametric Estimation of the Friend Attitude Effect}

I use nonparametric regressions to further assess any nonlinear relationship between friend attitudes and attitudes. To avoid the curse of dimensionality, I use the residuals from corresponding regressions of attitudes, friend attitudes, and friends of friends' highest parental education on the controls and school fixed effects to partial out their effects. This does not allow me to explore nonparametrically how the relationship between the controls and attitudes varies but it reduces the computational burden for testing this relationship between attitudes and friend attitudes.

It is well known that in the case of instruments nonparametric regression suffers from the ill-posed inverse problem (Horowitz 2011). I first follow the suggestions of Henderson and Souto (2018) and employ a control function approach. In this approach, and after partialling out the controls and school fixed effects, I use a local-linear estimation with a Epanechnikov kernel and cross-validation for optimal band-width selection. ${ }^{64}$ In the second-stage, I take the nonparametric regression of attitudes on friend attitudes and the first-stage residuals.

The left panel of figure G1 plots the fitted values of this second-stage nonparametric regression against friend attitudes. Here we see that attitudes increase with friend attitudes but it appears at a decreasing rate. ${ }^{65}$ However, the nonlinearity exhibited with the nonparametric control function approach is still not entirely clear.

Methods exist attempting to surmount the problems of instrumental variables with nonparametric regression. ${ }^{6}$ The method I follow is to regress the outcome on transformations of the endogenous variable utilizing transformations of the instrument. One can use either a B-spline or a polynomial basis and must select the degree of the spline basis for both the endogenous regressor and the instrument (Chetverikov, Kim, and Wilhelm 2018). Additionally, if using the B-spline approach, the number of equally spaced knots must also be selected for both the endogenous regressor and instrument.

In panel A of figure G1, I report these results where the estimates are computed within gridpoints over the 5 th to 95 th percentile range of friend attitudes. I estimate the effect using the polynomial basis for the endogenous regressor and instrument with powers of 2,3 and 3,4 and 4,5 respectively. These return largely similar plots of the fitted values of attitudes over friend attitudes. In general, attitude increases but

64. Standard errors are calculated from 100 bootstrap replications.

65. This is consistent with the plot in figure $\mathrm{H} 1$ which shows that the effect size of friend attitudes is falling as friend attitudes reach higher levels with a 3rd-order polynomial in friend attitudes included.

66. See (Horowitz 2011) for a survey. 

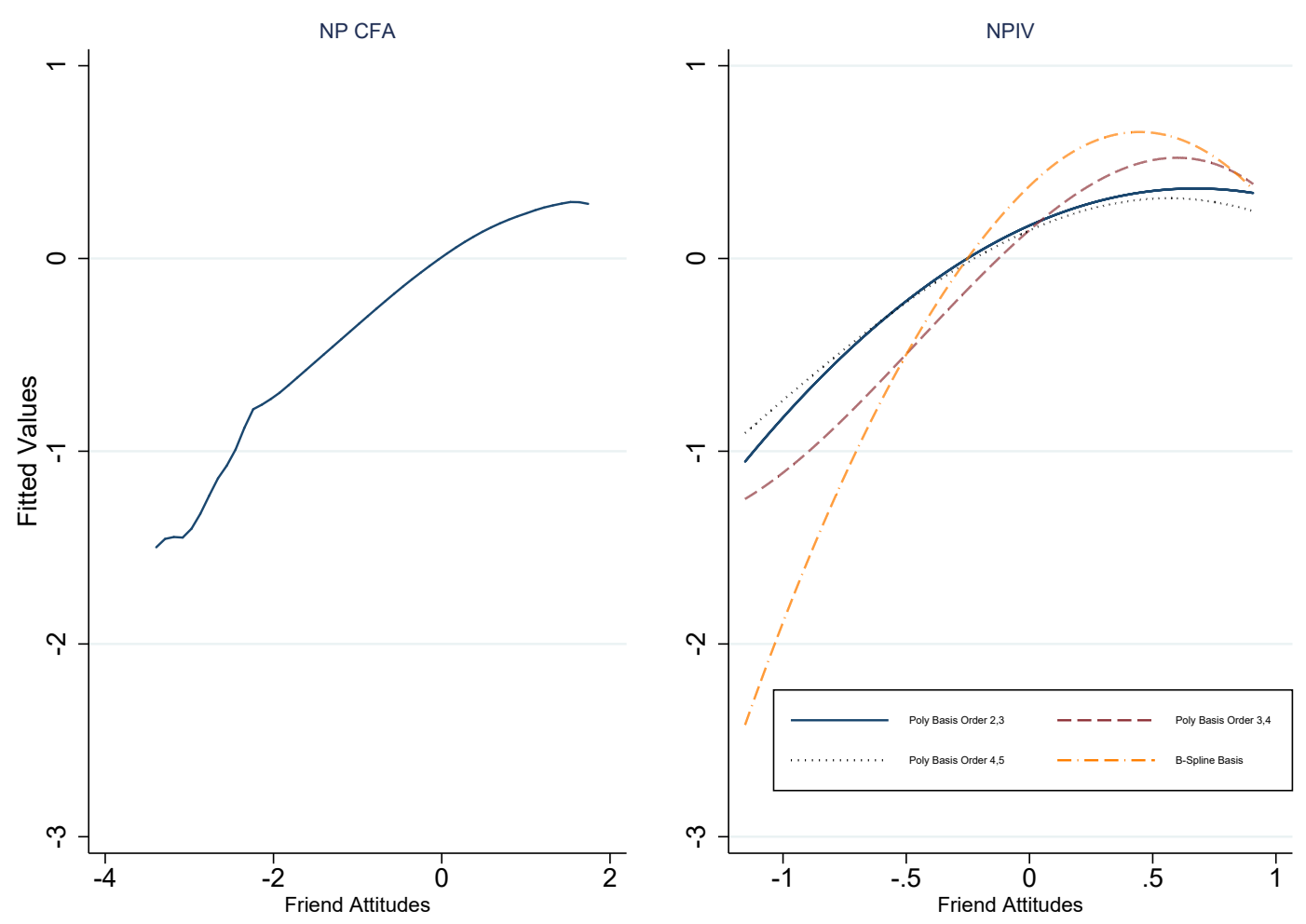

Figure G1: Nonparametric Results Correcting for Endogeneity

at a decreasing rate and may even begin to turn downward at high-levels of friend attitudes. To check this result, I also employ a B-Spline basis defining degrees at 2 and 3 and the number of knots at 3 and 4 for the endogenous and instrumental variables respectively. Again, while we see a slightly more pronounced dip once attitudes are sufficiently high, the general pattern is consistent with the previous results. 


\section{H Nonlinear Effects}

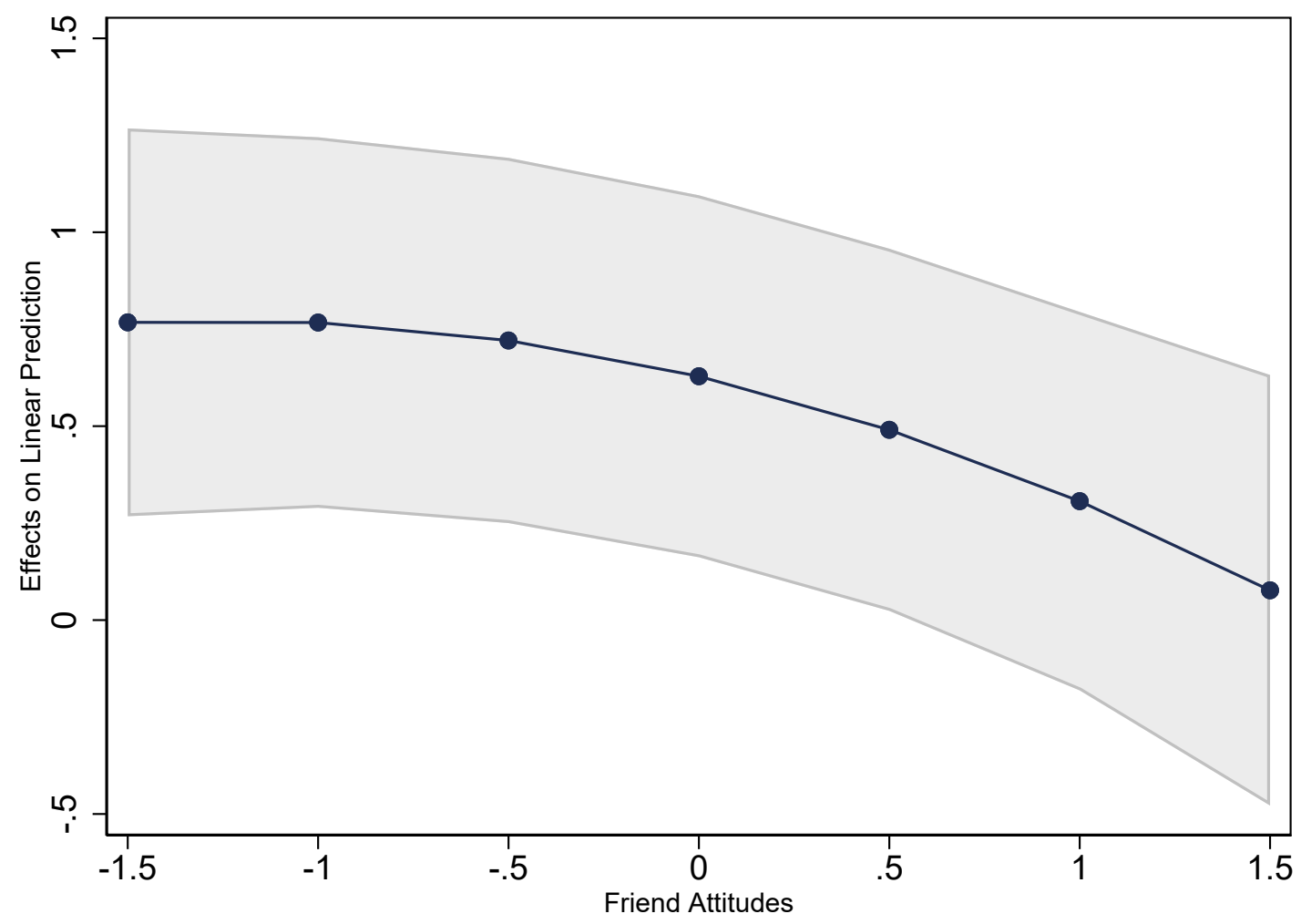

Figure H1: Nonlinear Effects of Friend Attitudes (3rd-Order Polynomial)

Note: This figure presents marginal effect estimates for mean friend attitudes on own-attitudes from 1.5 standard deviations above and below the average in half standard deviation steps. The shaded area plots the $95 \%$ confidence intervals. The specification is that used in column 2 of table 5 


\section{Robustness Checks: Friends and Peers Parents}

Table I1: Friend Attitudes and School-Grade Peers' Parents Robustness Checks

\begin{tabular}{|c|c|c|c|c|}
\hline $\begin{array}{l}\text { D.V. } \\
\quad=\text { Attitudes }\end{array}$ & $\begin{array}{c}(1) \\
\text { Parental } \\
\text { Expectations }\end{array}$ & $\begin{array}{c}(2) \\
\text { Maternal } \\
\text { Expectations }\end{array}$ & $\begin{array}{c}(3) \\
\text { Maternal } \\
\text { Involvement }\end{array}$ & $\begin{array}{c}(4) \\
\text { Parental } \\
\text { Involvement }\end{array}$ \\
\hline \multicolumn{5}{|l|}{$\begin{array}{l}\text { Panel A: Drop Parent } \\
\text { Variable as Control }\end{array}$} \\
\hline Friend Attitudes (GY) & $\begin{array}{l}0.724^{* *} \\
(0.345)\end{array}$ & $\begin{array}{l}0.779^{* *} \\
(0.310)\end{array}$ & $\begin{array}{l}0.591^{*} \\
(0.309)\end{array}$ & $\begin{array}{c}0.589^{*} \\
(0.310)\end{array}$ \\
\hline $\begin{array}{l}\text { Friend Attitudes } \\
\text { X SG Parent }\end{array}$ & $\begin{array}{l}-0.334^{* *} \\
(0.156)\end{array}$ & $\begin{array}{l}-0.466^{* *} \\
(0.193)\end{array}$ & $\begin{array}{l}-0.024 \\
(0.203)\end{array}$ & $\begin{array}{l}-0.048 \\
(0.190)\end{array}$ \\
\hline SG Parent & $\begin{array}{l}0.209^{* *} \\
(0.090)\end{array}$ & $\begin{array}{l}0.225^{* *} \\
(0.107)\end{array}$ & $\begin{array}{l}-0.001 \\
(0.110)\end{array}$ & $\begin{array}{c}0.037 \\
(0.110)\end{array}$ \\
\hline $\mathrm{KP}-\mathrm{F}$ & 7.462 & 14.144 & 9.867 & 10.314 \\
\hline \multicolumn{5}{|l|}{$\begin{array}{l}\text { Panel B: Add } \\
\text { SG Peer Controls }\end{array}$} \\
\hline Friend Attitudes (GY) & $\begin{array}{l}0.697^{* *} \\
(0.353)\end{array}$ & $\begin{array}{l}0.722^{* *} \\
(0.310)\end{array}$ & $\begin{array}{l}0.563^{* *} \\
(0.274)\end{array}$ & $\begin{array}{l}0.565^{* *} \\
(0.285)\end{array}$ \\
\hline $\begin{array}{l}\text { Friend Attitudes } \\
\text { X SG Parent }\end{array}$ & $\begin{array}{l}-0.424^{* *} \\
(0.179)\end{array}$ & $\begin{array}{l}-0.524^{* *} \\
(0.213)\end{array}$ & $\begin{array}{l}-0.027 \\
(0.179)\end{array}$ & $\begin{array}{l}-0.037 \\
(0.187)\end{array}$ \\
\hline SG Parent & $\begin{array}{l}0.319^{* * *} \\
(0.118)\end{array}$ & $\begin{array}{l}0.314^{* *} \\
(0.130)\end{array}$ & $\begin{array}{c}0.043 \\
(0.108)\end{array}$ & $\begin{array}{c}0.099 \\
(0.117)\end{array}$ \\
\hline Parent Variable & $\begin{array}{l}0.111^{* * *} \\
(0.028)\end{array}$ & $\begin{array}{l}0.134^{* * *} \\
(0.029)\end{array}$ & $\begin{array}{l}0.148^{* * *} \\
(0.028)\end{array}$ & $\begin{array}{l}0.166^{* * *} \\
(0.028)\end{array}$ \\
\hline $\mathrm{KP}-\mathrm{F}$ & 5.088 & 9.395 & 10.742 & 9.438 \\
\hline
\end{tabular}

